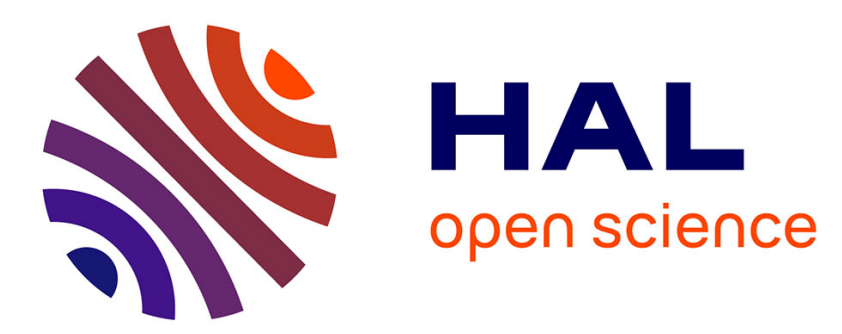

\title{
Porous polymers and metallic nanoparticles: A hybrid wedding as a robust method toward efficient supported catalytic systems
}

\author{
Romain Poupart, Daniel Grande, Benjamin Carbonnier, Benjamin Le
}

Droumaguet

\section{To cite this version:}

Romain Poupart, Daniel Grande, Benjamin Carbonnier, Benjamin Le Droumaguet. Porous polymers and metallic nanoparticles: A hybrid wedding as a robust method toward efficient supported catalytic systems. Progress in Polymer Science, 2019, 96, pp.21-42. 10.1016/j.progpolymsci.2019.05.003 . hal02157146

\section{HAL Id: hal-02157146 \\ https://hal.science/hal-02157146}

Submitted on 5 Jul 2021

HAL is a multi-disciplinary open access archive for the deposit and dissemination of scientific research documents, whether they are published or not. The documents may come from teaching and research institutions in France or abroad, or from public or private research centers.
L'archive ouverte pluridisciplinaire HAL, est destinée au dépôt et à la diffusion de documents scientifiques de niveau recherche, publiés ou non, émanant des établissements d'enseignement et de recherche français ou étrangers, des laboratoires publics ou privés. 


\title{
Porous Polymers and Metallic Nanoparticles: a Hybrid Wedding as a Robust Way Toward Efficient Supported Catalytic Systems
}

\author{
Romain Poupart, Daniel Grande, Benjamin Carbonnier, Benjamin Le Droumaguet*
}

Université Paris Est, Institut de Chimie et des Matériaux Paris-Est (ICMPE), UMR 7182, CNRS, UPEC, F- 94320 THIAIS France

Submitted as a review article to Progress in Polymer Science

* Corresponding author: Dr. Benjamin Le Droumaguet

Phone: $+33(0) 149781177$

Fax: +33 (0)1 49781208

E-mail: ledroumaguet@icmpe.cnrs.fr 
Abstract: Over the past recent years, nanoparticles have been the subject of numerous studies, due to their unique intrinsic properties. In particular, they have found widespread interest in heterogeneous catalysis, and their development in this area is growing. Nevertheless, they still display drawbacks and, among them, the question of their recyclability may arise. In order to avoid tedious filtration steps, metallic nanoparticles may be advantageously supported on miscellaneous porous materials. Polymer materials can be envisaged as versatile and effective supports, due to their low production cost and easy functionalization. This review will first focus on different types of porous polymers developed in view of their further use as catalytic supports. Then, a brief description of the nanoparticles synthesis will be addressed, before a presentation of typical examples reported in the literature about metallic nanoparticles immobilized on porous polymers meant for heterogeneous supported catalysis.

Keywords: Porous polymers; Metallic nanoparticles; Hybrid materials; Supported heterogeneous catalysis 
AM

ATRP

BCP

BET

BJH

CEC

DABCO

DMF

DMSO

DSC

DSDMA

DTT

EGDMA

GCMA

GMA

HEMA

HIPE

IUPAC

MIP

NAS

NMR

NP

PEI acrylamide

atom transfer radical polymerization

block copolymer

Brunauer-Emmett-Teller

Barrett-Joyner-Halenda

capillary electrochromatography

1,4-diazabicyclo[2.2.2]octane

$N, N$-dimethylformamide

dimethylsulfoxide

differential scanning calorimetry

disulfide-based dimethacrylate (bis(2-methacryloyl)oxyethyl disulfide)

D,L-dithiothreitol

ethylene glycol dimethacrylate

glycerol carbonate methacrylate

glycidyl methacrylate

2-hydroxyethyl methacrylate

high internal phase emulsion

International union of pure and applied chemistry

mercury intrusion porosimetry

$\mathrm{N}$-acryloxysuccinimide

nuclear magnetic resonance

nanoparticle; PAA, poly(acrylic acid)

poly(ethylene imine) 
poly(ether sulfone)

PI

polyisoprene

PLA

$\operatorname{poly}(\mathrm{D}, \mathrm{L}-$ lactide $)$

PMMA

poly(methyl methacrylate)

PS

polystyrene

PVA

poly(vinyl alcohol)

RAFT

reversible addition-fragmentation chain transfer

ROMP

ring opening metathesis polymerization

ROP

ring opening polymerization

SEM

scaning electron microscopy

TEOS

tetraethyl orthosilicate

TFA

trifluoroacetic acid

THF

tetrahydrofuran

TIPS

temperature-induced phase separation

TON

turnover number

UV

ultraviolet

VBC or $4-\mathrm{VBC}$

4-vinylbenzyl chloride

VDMA

2-vinyl-4,4-dimethylazlactone 


\section{Contents}

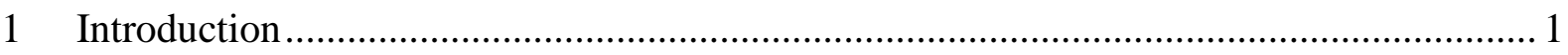

2 Porous polymers: general features, synthesis, and characterization ............................. 5

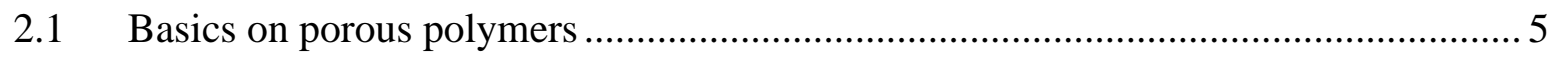

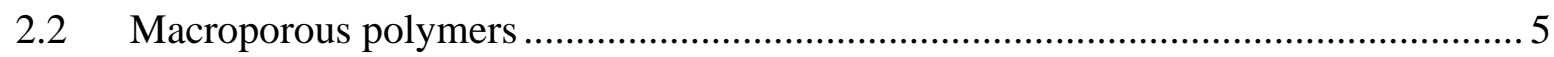

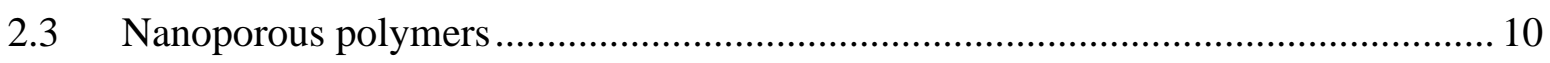

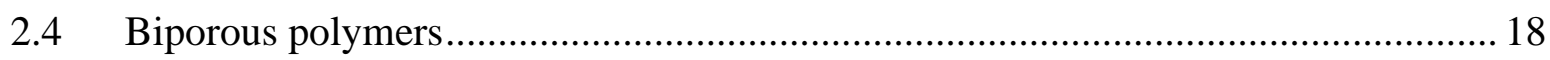

2.5 Characterization techniques of porous materials .............................................. 23

3 Application of metallic nanoparticle immobilized on porous polymers as supported

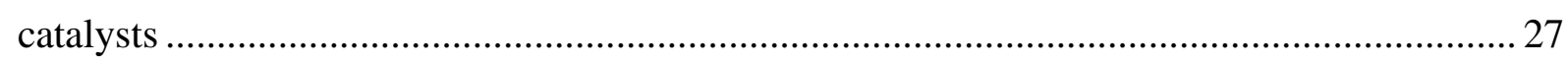

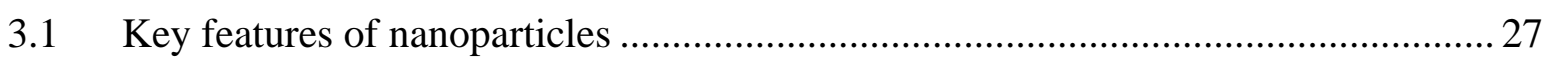

3.2 Nanoparticles supported by macroporous polymers ........................................ 31

3.3 Nanoparticles supported by nanoporous polymers .......................................... 40

3.4 Nanoparticles supported by biporous polymers ............................................. 46

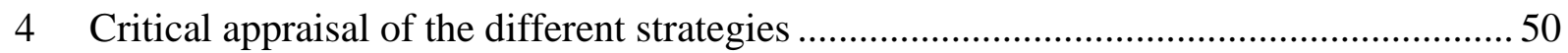

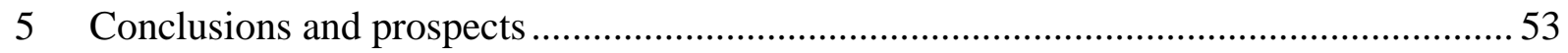

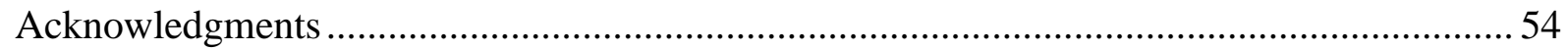

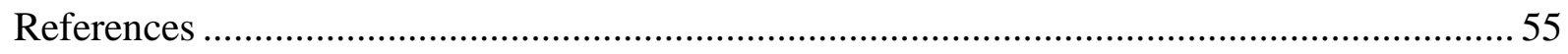




\section{Introduction}

A catalyst is commonly described by the International Union of Pure and Applied

3 Chemistry (IUPAC) as a substance that increases the rate of a reaction without modifying the

4 overall standard Gibbs energy change in the reaction. Two different types of catalytic

5 processes actually exist: $(i)$ one type based on homogeneous catalysis, namely the catalyst is

6 present in the same phase as the reactants, mostly a liquid phase [1], while (ii) the other type

7 is named as heterogeneous when the catalyst and the reactants are in different phases.

8 Though, the frontier between both kinds of processes can be sometimes really thin in

9 particular cases [2]. The metal-based catalyst is mostly in the solid state, finely divided, and

10 the reactants are in the liquid or gaseous one. Nevertheless, some examples of heterogeneous

11 biphasic catalysis reported that the catalyst remains in one liquid phase (i.e. water) and

12 reactants in another one (i.e. oil), such as for the hydroformylation of propene, for instance

13 [3]. One such example illustrates very well the possibility to perform catalysis by phase

14 transfer. Recent developments in this research area notably demonstrated that catalytic

15 reactions, especially organometallic-based ones, can be carried out in more environmentally-

16 friendly conditions than a few years ago [4]. Such catalytic reactions more and more call upon

17 green and sustainable chemistry, and efforts have been put forward in this direction to address

18 specific issues related to the recycling of the catalysts.

19 In this context, supported metallic nanoparticles present some undeniable advantages

20 regarding heterogeneous catalysis. They have actually shown an increasing interest over the

21 last decade. Such nanometer-sized metallic particles, immobilized on high surface area

22 materials, can now be relatively well characterized by different techniques and have shown

23 some great catalytic performances. The preparation of such hybrid materials involves the

24 design and development of still novel and efficient catalysts, and thus the improvement of

25 (in)organic supports in terms of specific surface area, porosity, surface functionality and 
1 chemical inertness towards a wide variety of versatile or harsh reaction conditions [5].

2 Catalytic systems are commonly used in various industrial techniques [6] as well as in our 3 common life, as demonstrated by automotive catalytic converters for instance [5]. While a

4 serious drawback has been encountered with suspended nanoparticles, i.e. the recycling of the

5 nanometal catalyst through time-consuming and non-environmentally friendly purification

6 processes, miscellaneous solutions exists. First, a recently reported solution to address this

7 issue relies on the use of nanoparticles bearing a magnetic core, generally $\gamma-\mathrm{Fe}_{2} \mathrm{O}_{3}$. In this

8 case, the nanometal recovery step can be achieved by harvesting with the help of a magnet.

9 However, a coating (silica, carbon, or polymer) of these magnetic metallic nanoparticles is 10 generally required to allow for their suspension in a stable fashion, thus avoiding their 11 coalescence, and protecting them from the surrounding environment. When a polymer coating 12 is implemented for such magnetic nanoparticles, the resulting coated particles are not stable in 13 harsh reaction conditions, such as at high temperature. The same observations have been 14 made with silica coatings that are porous. Such an inorganic coating has a very low stability in 15 harsh $\mathrm{pH}$ conditions. Finally, when carbon-based coatings are used for magnetic 16 nanoparticles, they aim at agglomerating and form clusters, which would lead to a decrease of 17 specific surface area of the catalysts [7]. Then, another solution consists in using macroscopic porous matrices as supports for the immobilization of metallic nanoparticles at the pore surface. The robust and straightforward immobilization of nanoparticles at the pore surface of suitable supports, notably by tuning the nature of the interface, enables to further avoid 21 tedious purification processes, as the supported catalyst can be readily removed from the 22 reaction mixture by mere filtration. Hybrid catalysts based on supported metallic nanoparticles generally consist of 24 (in)organic/hybrid porous frameworks presenting a rather high specific surface area that 25 allows for a large amount of metallic nanoparticles to be immobilized in a straightforward and 
1 robust fashion. Among such high specific surface area supports, inorganic materials like

2 zeolites [8] or ordered mesoporous silicas [9] can be found. Zeolites possess pores within the

3 microporous range, enabling them to be used as catalyst supports in liquid or gas reaction

4 conditions. Even though zeolites can be synthetized in rather mild temperature conditions

$5 \quad\left(90-180^{\circ} \mathrm{C}\right)$, their preparation requires pressures up to 15 bars in autoclaves. Other inorganic

6 supports like mesoporous silicas can be prepared in a straightforward fashion by reacting in a

7 first step a surfactant typically arising from the Tween ${ }^{\circledR}$ or Pluronic ${ }^{\circledR}$ family and a precursor mainly tetraethyl orthosilicate (TEOS) in mild conditions [10]. However, the major concern of such porous inorganic supports relies on the harsh reaction conditions required in the calcination step that enables for the disappearance of the organic surfactant and thus the generation of the porosity. The calcination step is indeed performed at very high temperatures, i.e. hundreds of ${ }^{\circ} \mathrm{C}$, for several hours, which is highly energy- and time-consuming. On the other hand, organic polymer-based supports as well as modified carbon nanotubes [11] have been recently developed. Finally, hybrid structures, i.e. Metal-Organic Frameworks [12] (MOFs) have been more recently deeply investigated in heterogeneous supported catalysis applications, due to their versatility and remarkably high surface area. Unfortunately, this class of hybrid materials suffers from high fabrication costs, poor selectivity, low capacity, and difficulty in recycling/regeneration [13].

In the case of polymeric materials, some advantages rapidly come to mind. They can first be easily functionalized so as to tune the pore surface chemistry, which is of upmost 21 importance for further adsorption of chemical species or metallic nanoparticles. One can also easily play with the hydrophilic/hydrophobic nature of the polymer interface that will have some consequences on the interaction with the surrounding fluid, notably in terms of wettability. The porosity can also be readily varied in terms of pore size, ratio, and shape. Such polymeric materials are generally cross-linked, allowing for a better stability of the 
1 resulting hybrids in miscellaneous experimental conditions such as harsh $\mathrm{pH}$ or temperature.

2 Finally, such polymer-based porous supports have mechanical properties tunable in a useful 3 range, and their production cost is lower than that of their inorganic analogues. On the

4 opposite, some drawbacks can be noticed with such porous polymers: they cannot generally 5 resist to high pressure and temperature, rendering some catalytic chemical reactions on these

6 supports difficult to envision. However, they still remain common porous supports for 7 metallic nanoparticles immobilization and are thus the subject of widespread interest in the 8 field of heterogeneous catalysis.

In light of this general introduction, this review will focus on the design and synthesis of hybrid materials consisting of metallic nanoparticles immobilized at the pore surface of 11 porous polymers for catalytic reaction purposes. A first section will be devoted to general 12 features about porous polymer-based materials; then the main strategies to prepare such 13 porous supports and the associated techniques of characterization will be presented. The 14 reader should bear in mind that this section will not give a full overview of all strategies 15 implemented for the synthesis of porous polymers, but it will rather focus on those mainly 16 used for the preparation of porous polymeric systems meant for supported catalysis 17 applications. It is thus recommended for casual readers to refer to more general reviews on porous polymers to get a full overview of their preparation routes [14]. A second section will

19 then be directed towards the use of hybrid porous materials obtained after metallic 20 nanoparticles immobilization at the pore surface of polymeric supports, and their further 21 implementation in heterogeneous catalysis. 


\section{Porous polymers: general features, synthesis, and characterization}

\section{$2 \quad 2.1 \quad$ Basics on porous polymers}

According to the IUPAC [13], porous solid materials can be classified into three main

4 categories. Firstly, microporous materials are characterized by pore diameters below $2 \mathrm{~nm}$.

5 Secondly, the term "mesoporous" is used to qualify materials with pore diameters between 2

6 and $50 \mathrm{~nm}$. Finally, macroporous materials can be distinguished by a pore diameter larger

7 than $50 \mathrm{~nm}$. It is at this stage very important to note that this classification is the only one that

8 is commonly admitted by the scientific community. However, in the areas of materials science

9 and nanotechnologies, the term "nanoporous" is commonly applied to materials containing

10 pore sizes lower than $100 \mathrm{~nm}$, even though such a terminology can be somehow confusing for

11 casual readers and even experts in the field. Likewise, materials with porosity in the 12 micrometer range (or more) are often called macroporous materials. This general 13 classification can be applied to any type of porous material, namely inorganic, hybrid or 14 organic ones.

\subsection{Macroporous polymers}

Macroporous materials may be prepared by different techniques through the use of miscellaneous porogens. In 1967, Seidl et al. [15] distinguished three main synthetic strategies to prepare porous polymeric matrices: $(i)$ by using a porogenic solvent, (ii) by using a non-solvent as the porogen or (iii) by adding a linear polymer as a macromolecular porogen.

21 According to Švec and Fréchet, these synthetic strategies are the most commonly used, but 22 above all they are easy to implement [16].

When a solvent is used as a porogenic agent, the initiator, monomer(s) and cross-

24 linker are dissolved in a solvent or in a solvent mixture. When the polymerization is triggered 25 by photochemical or thermal decomposition of the initiator, polymeric particles nucleate, 
1 grow, and coalesce in the solvent. Depending on the affinity of the solvent for the growing 2 cross-linked polymer, the former will be ejected more or less promptly from the polymer 3 matrix through a syneresis phenomenon, creating voids filled with solvent. Upon porogenic 4 solvent removal, these voids generate the porosity within the polymeric material. As the 5 moment of the solvent ejection is closely related to the solvent and polymer compatibility, the 6 pore size of the resulting materials can be thus easily tuned by merely changing the solvent 7 polarity. In addition, the porosity ratio will also be dictated by the comonomers/(co)solvent(s) 8 volume ratio. Finally, the porosity can be open or closed, depending on the amount of 9 porogenic agent chosen. For very low porogenic solvent(s) to (co)monomers ratio, it is particularly true.

Such a way of generating porosity within polymeric materials has been widely implemented notably for preparing polymer-based monolithic columns with an interconnected porosity. This enables liquids or gases to easily flow through such monolithic columns, depending on the average pore size of the material as well as on the viscosity of the solvent, to avoid too high back pressures. Different monolithic columns have been prepared so far following this synthetic strategy, whatever the nature of the monomer used. Generally, the monomer is functional, that is to say it possesses a chemical moiety that can be easily chemically modified through a post-polymerization step consisting of a reaction occurring at the interface of the pore with the surrounding fluid, allowing for the interfacial properties of the pore surface to be easily tuned. Historically, the first monolithic capillaries were prepared by Švec's research group in the mid-1990's using glycidyl methacrylate (GMA) as a functional monomer [17]. GMA bears an epoxide moiety that can be easily functionalized through ring-opening reaction with rather strong nucleophiles like amines [17]. Later on, the same research group has deeply expanded his pioneering works on the exploitation of GMA monomer, notably for chromatographic applications [18]. It is now used in other laboratories 
$1[19,20]$, allowing for a plethora of potential applications to be envisioned. In the late 1990's,

2 4-chloromethyl styrene, also known as 4-vinylbenzyl chloride (4-VBC or VBC), was

3 investigated in applications related to monolithic columns [21]. This styrenic monomer gave

4 birth to highly hydrophobic columns, while the pore surface of the resulting materials can be

5 easily tuned by nucleophilic substitution of the benzylic chlorine. It is worth mentioning that

6 such functionalization reactions can lead to hypercrosslinked materials, provided that the

7 chemical graft to anchor possesses two identical reactive groups [22]. 2-Vinyl-4,4-

8 dimethylazlactone (VDMA) is another interesting monomer used for the preparation of

9 porous materials [23]. Indeed, VDMA can be readily incorporated into the composition of

10 polymerization mixtures in conjunction with diverse hydrophilic monomers, e.g. 2-

11 hydroxyethyl methacrylate (HEMA) and acrylamide (AM), to prepare functional in-capillary

12 monoliths that can be functionalized with amine bearing bio(macro)molecules [23]. Finally,

$13 \mathrm{~N}$-acryloxysuccinimide (NAS) and glycidyl carbonate methacrylate (GCMA) have been more

14 recently implemented for the design of innovative functional porous in-capillary columns, as

15 shown in Fig. 1A [24]. NAS can undergo nucleophilic substitution due to the presence of

16 pendant activated ester moieties and has been widely used for chromatographic applications,

17 such as capillary electrochromatography (CEC) separations [25-30] or for flow through

18 catalysis applications [31]. Alternatively, oligomeric or polymeric chains have also been used

19 as porogens in other studies (Fig. 1B) [32, 33]. 

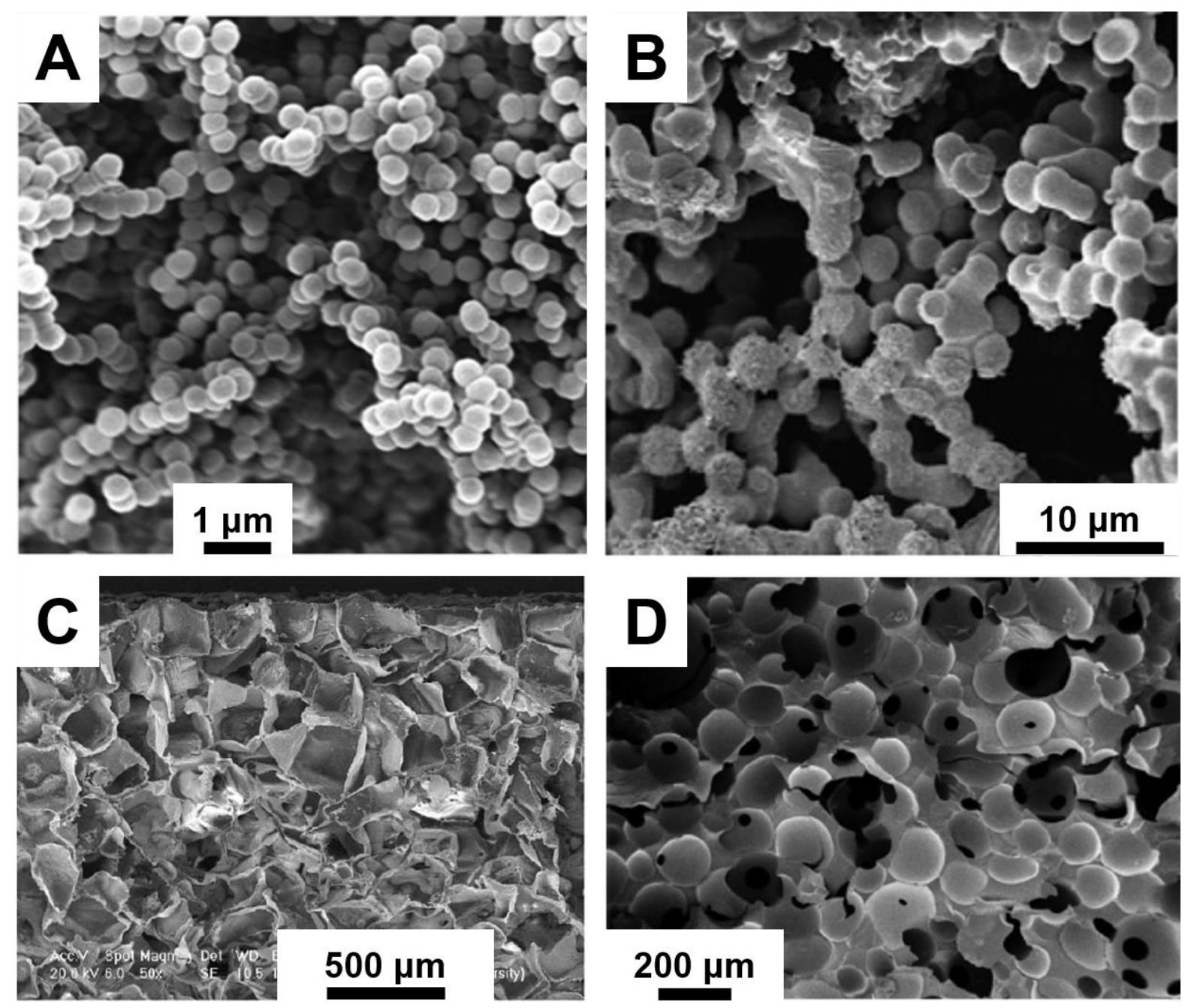

2 Fig. 1. Examples of macroporous polymeric materials derived from the use of porogenic 3 agents. (A) $\mathrm{N}$-acryloylsuccinimide-based monoliths obtained in the presence of a porogenic

4 solvent. [24], Copyright 2007 (Reproduced with permission from Elsevier Ltd). (B)

5 polystyrene macroporous monolith obtained after leaching of a semi-interpenetrated

6 polycaprolactone oligomer. [32], Copyright 2010 (Reproduced with permission from Elsevier

7 Ltd). (C) Poly(D,L-lactic-co-glycolic acid)-based frameworks using $\mathrm{NaCl}$ cubic particles as 8 macroporogens [34]. Copyright 2005. Reproduced with permission from Elsevier Ltd. (D)

9 Porous poly(2-hydroxyethyl methacrylate) material obtained upon removal of sintered 10 poly(methyl methacrylate) beads as 3-D macroporogenic template. [35], Copyright 2014 11 (Reproduced with permission from Elsevier Ltd).

Other porogens than those defined by Seidl and coworkers are nowadays commonly 14 used for different purposes. Especially, macroporogen templating has gained a tremendous 
1 interest in the last years. It relies on the use of a so-called template which acts as a

2 macroporogen. It is added to the initial polymerization mixture (consisting of the initiator, the

3 (co)monomer(s) and the cross-linker(s)) and immediately removed after the polymerization

4 completion. The judicious choice of this porogenic template notably allows for tuning the

5 pore morphology as the pores will present a shape that perfectly matches the template imprint.

6 Such porogenic templates are based on solid, mostly inorganic crystal particle, such as sodium

7 chloride $(\mathrm{NaCl})$ [36], calcium carbonate $\left(\mathrm{CaCO}_{3}\right)$ [37] or ammonium bicarbonate $\left(\mathrm{NH}_{4} \mathrm{HCO}_{3}\right)$

8 [36] particles, for instance. The use of such a methodology presents some non-negligible

9 advantages as it permits to vary the size (by particle sieving) and morphology (depending on

10 the shape of selected porogen) of the pores, while their removal is generally simple to achieve

11 through easy template leaching into an appropriate aqueous solution. In fact, they are usually

12 dissolved in pure water through particle leaching, such as for the extraction of $\mathrm{NaCl}$ particles.

13 Alternatively, $\mathrm{CaCO}_{3}$ particle-based templates require an acidic aqueous solution to be

14 removed from the polymer matrix. It is worth mentioning that the porogenic template could

15 also be prepared with the desired shape [34] (Fig. 1C). As a matter of fact, other

16 investigations reported on the use of different sacrificial templates derived from organic

17 (macro)molecules, such as paraffin or poly(methyl methacrylate) (PMMA) beads. In this case,

18 the porogen could also be dissolved via Soxhlet extraction with an appropriate organic

19 solvent. LaNasa et al. [38] and Le Droumaguet et al. [35] independently demonstrated that it

20 is possible to successfully use sintered polymeric PMMA beads as an original porogenic

21 template (Fig. 1D). Such sintered PMMA beads could further be extracted in organic

22 solvent(s), while the porous polymeric matrix remains intact, due to permanent cross-linking.

23 These sintered spherical beads allowed for the generation of interconnected spherical pores

24 upon removal of the macroporogen. 


\subsection{Nanoporous polymers}

Miscellaneous approaches have been developed so far to prepare nanoporous polymerbased materials. These materials are mostly used as filtration membranes. In this particular case, the process is subtler than for the preparation of macroporous materials, and it usually involves the removal of a sacrificial polymer segment from nanostructured precursors, thus generating pores at the nanoscale level. Techniques like track-etching which lead to nanopores will not be addressed here, but reviews discussing the subject may be easily found [39].

A largely investigated strategy consists in specifically removing one sacrificial block from oriented block copolymers (BCPs), thus leading to ordered nanoporous materials via a process milder than that used with other strategies. BCPs and especially diblock copolymers develop very precise equilibrium domain morphologies depending on three main critical parameters, i.e. the volume fraction of both blocks $f$, the number of repeating units $N$ in the copolymer, and $\chi_{A B}$ the Flory-Huggins interaction parameter between the two different blocks [40]. According to theoretical phase diagrams, body-centered spheres, hexagonally closepacked cylinders, bicontinuous gyroids or alternating lamellae can be obtained (Fig. 2) [41, 42]. Polydispersity of both blocks is also a key parameter to precisely control the morphology of the block copolymers after orientation of the nanodomains. Indeed, a high polydispersity of the minority block has been shown to lead to a change of morphology due to a larger interfacial curvature [43]. On the opposite, a high polydispersity of the majority one was demonstrated to lead to a change of morphology due to a smaller interfacial curvature. So far, different natures of sacrificial blocks have been implemented to prepare nanoporous materials from this strategy. Historically, the first diblock copolymer precursors used were constituted

of a degradable polyisoprene (PI) block and of a stable polystyrene-derived (4vinylphenyl)dimethyl-2-propoxysilane) block, both synthetized by anionic polymerization. 
1 The former block was removed by ozonolysis that selectively cleaved the carbon-carbon

2 double bonds of the isoprene units, while the polystyrene (PS) segment was simultaneously

3 crosslinked, thus revealing nanoporous PS-based networks [44]. Later on, other research

4 groups have successfully developed other sacrificial blocks by varying the conditions of 5 etching [45]. Herein, we will focus on poly(D,L-lactide) (PLA), which has been widely used 6 in the area of nanoporous polymers.

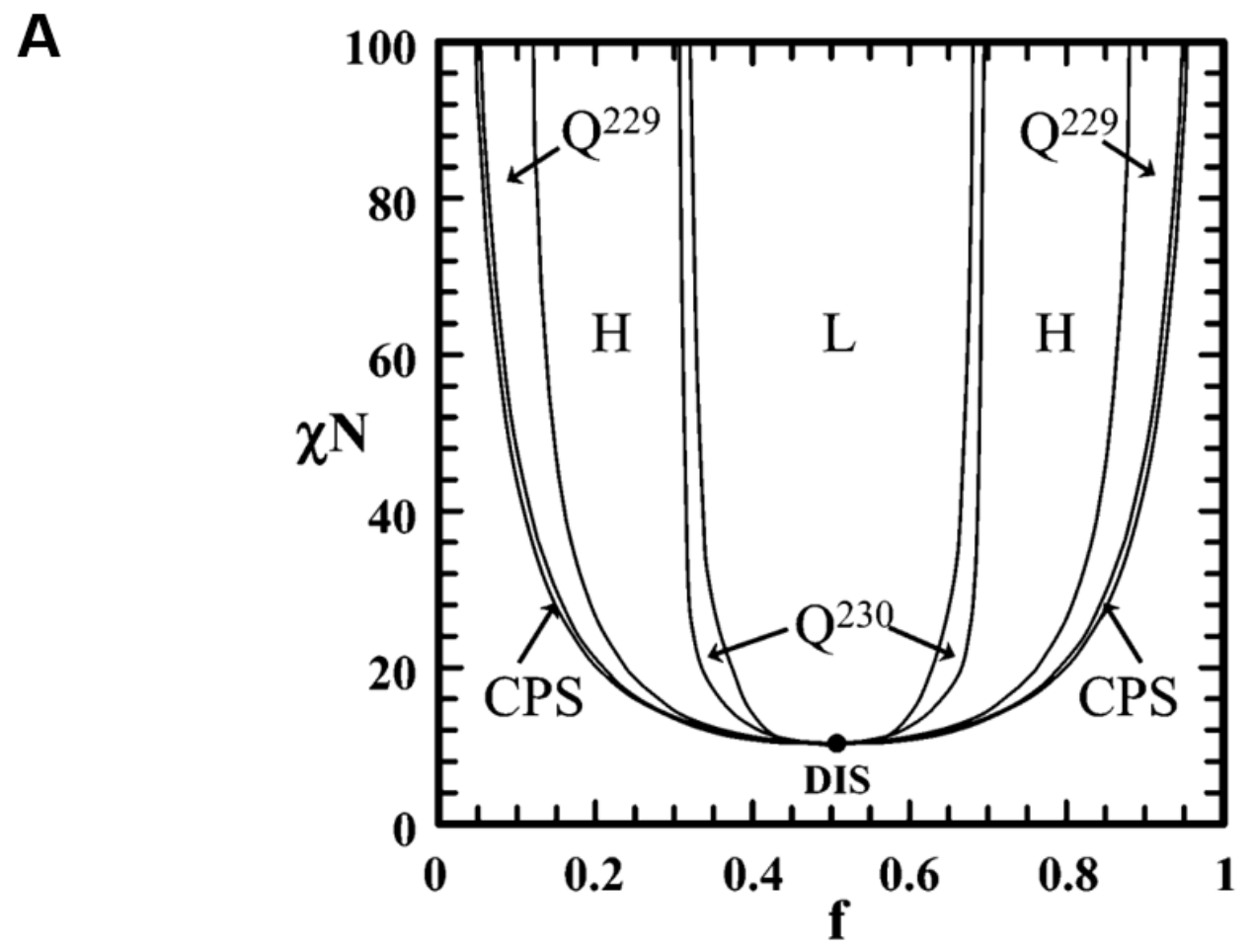

B
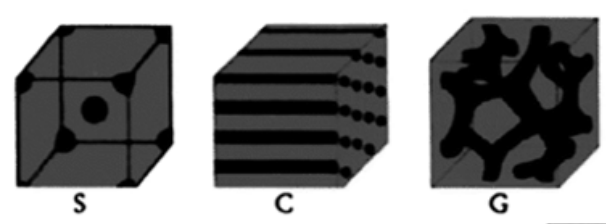

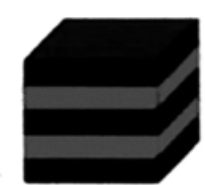

L

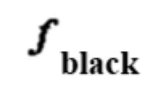

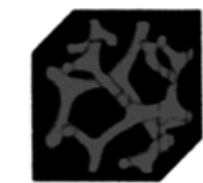

$G^{\prime}$

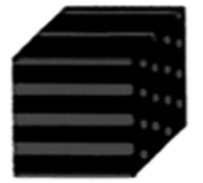

C'

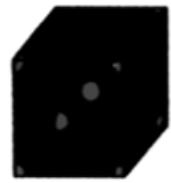

$s^{\prime}$

8 Fig. 2. (A) Morphology diagram of $A B$ diblock copolymers obtained upon orientation of respective BCP domains depending on the segregation regime $(\chi N)$ and the volume fraction of the minor component $(f)$ : $\mathrm{L}, \mathrm{H}, \mathrm{Q}^{229}, \mathrm{Q}^{230}$, CPS and DIS stand for lamellae, hexagonally

11 packed cylinders, spherical phases with $\operatorname{Im} 3 m$, 3D gyroid phase, close-packed (fcc or

12 hexagonal) symmetry, or disorder respectively. [42], Copyright 2006 (Reproduced with 13 permission from the American Chemical Society). (B) Schematic representation of the various 
1 possible morphologies depending on $f_{\text {black: }}$ S and S', C and C', G and G', L and L' stand for 2 spheres, cylinders, gyroïds and lamellae, respectively. [41], Copyright 1999 (Reproduced with 3 permission from the American Institute of Physics).

4

PLA can be synthetized via anionic or coordinative ring-opening polymerization 6 (ROP) of 3,6-dimethyl-1,4-dioxane-2,5-dione (usually called D,L-lactide), from alcohol- [46] 7 or amine-based [47] initiators in the presence of organic [48] or organo-metallic [49] 8 catalysts. PLA is generally etched in mild conditions, namely in alkaline conditions and 9 especially in $\mathrm{NaOH}$ or $\mathrm{KOH}$ hydro-alcoholic solutions, as described by numerous studies 10 from Hillmyer and coworkers first in 2001 [50] or later on from our research group [51, 52]

11 (Fig. 3A). It is worth noticing that PLA can also be degraded in acidic conditions. It is not 12 until recently that such etching conditions have been reported in the literature for PS- $b$-PLA $13[53]$. 

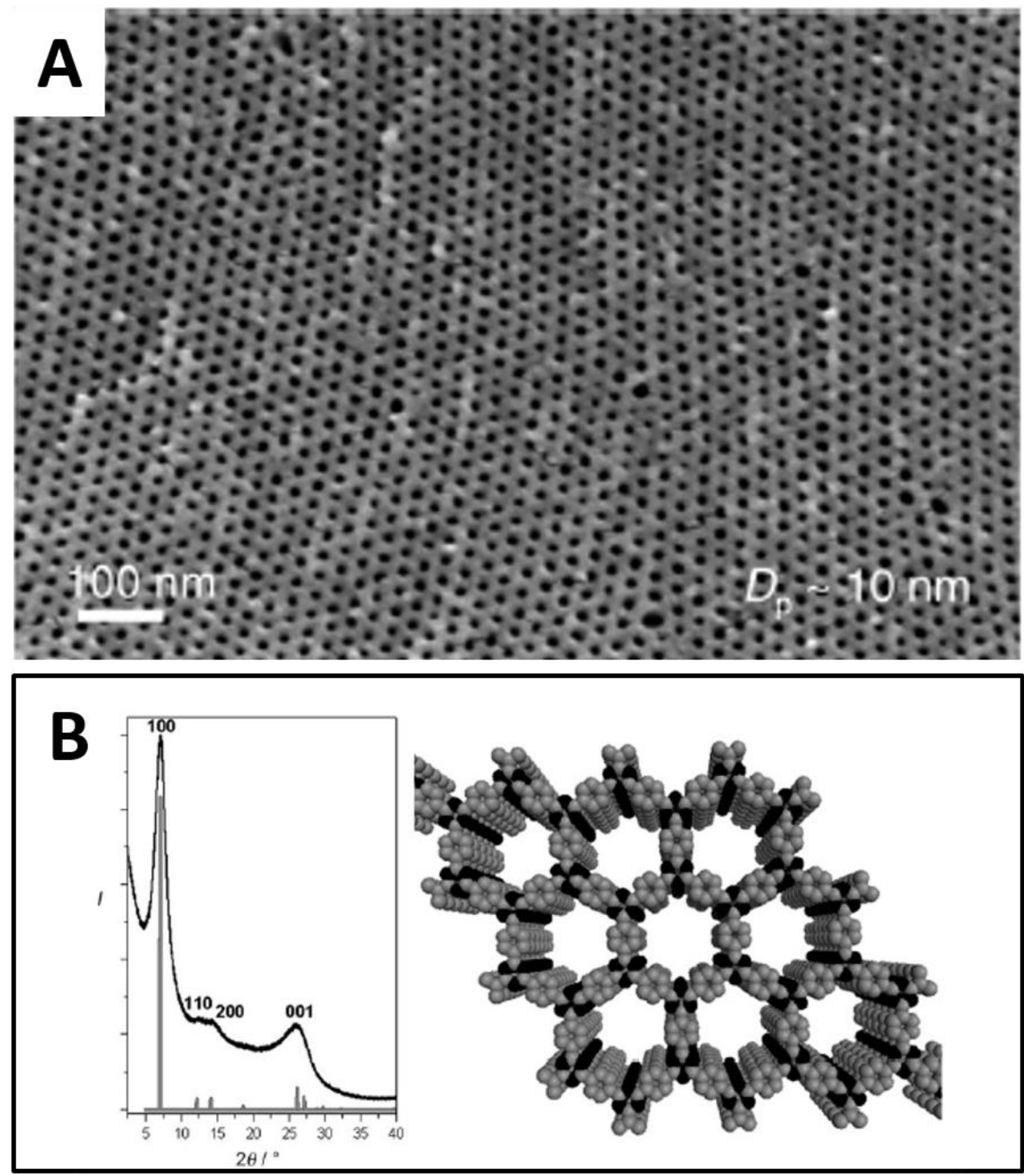

2 Fig. 3. Examples of nanoporous polymeric materials. (A) Nanopores arising from selective

3 hydrolysis of the PLA sacrificial block in a PS- $b$-PLA diblock copolymer. [51], Copyright

42011 (Reproduced with permission from Elsevier Ltd). (B) Nanopores arising from an

5 intrinsically microporous polytriazine network. [54], Copyright 2008 (Reproduced with 6 permission from Wiley-VCH publishers).

Another somehow smarter strategy to etch the sacrificial block from BCPs relies on

9 the selective cleavage of the junction present between both block. Indeed, the degradable

10 character of such a junction can lead to easy and straightforward removal of the entire

11 sacrificial block in a non-solvent of the remaining block. Such a strategy notably permits to 
1 carry out the sacrificial block removal in milder conditions than those employed for the

2 chemical degradation of the block itself and to ensure the presence of a well-defined

3 functional group at the pore surface. Russell's group pioneered this elegant strategy by

4 precisely positioning an anthracene photodimer at the junction between both blocks of a

5 polystyrene-block-poly(methyl methacrylate), the PMMA sacrificial block being further

6 released from the oriented diblock copolymers by dissociation of the photodimer under UV or

7 thermal stimuli, thus revealing nanopores [55]. Later on, different selectively cleavable

8 chemical junctions have been used in diblock copolymers. They can be categorized into three

9 main sub-classes. The first one relies on using an irreversibly cleavable junction between both

10 blocks (Table 1). Trityl ether [56, 57] which is easily cleavable by trifluoroacetic acid (TFA),

$11 o$-nitrobenzyl ester [58-60] or carbamate [61] derivative, hemiacetal junction [62] or acetal

12 moiety [63, 64] for instance have been successfully implemented in this context. Other 13 strategies involving reversible junctions have also been put forward, such as the 14 aforementioned $[4 \pi+4 \pi]$ anthracene photodimer [55, 65], disulfide bridges, [66, 67] oxi15 imines [68] or hetero Diels-Alder adducts arising from RAFT agents [69], for instance, as 16 depicted in Table 2. Finally, other investigations reported on the possibility to implement 17 supramolecular junctions to link both blocks in a non-covalent manner, as shown in Table 3. 18 We can notably mention the use of terpyridine-ruthenium [70] or terpyridine-nickel [71] 19 complexes, ionic interactions [72] or even hydrogen bonds [73] taking place between the two 20 adjacent blocks of oriented copolymers. 
1 Table 1. Irreversibly cleavable junctions used for the preparation of functionalized 2 nanoporous polymers.

\begin{tabular}{|c|c|c|c|c|}
\hline $\begin{array}{c}\text { Type of block } \\
\text { junction }\end{array}$ & $\begin{array}{c}\text { Junction chemical } \\
\text { structure }\end{array}$ & Cleavage agent/stimulus & $\begin{array}{l}\text { Chemical function } \\
\text { remaining after cleavage }\end{array}$ & References \\
\hline Trityl ether & & $\begin{array}{c}\text { Brønsted or Lewis acid } \\
\text { (ex: TFA) }\end{array}$ & Primary alcohol & {$[56,57]$} \\
\hline $\begin{array}{c}o \text {-nitrobenzyl } \\
\text { ester }\end{array}$ & & $\begin{array}{c}\text { UV light } \\
(\lambda=350 \mathrm{~nm})\end{array}$ & Carboxylic acid & {$[58-60,74]$} \\
\hline $\begin{array}{c}o \text {-nitrobenzyl } \\
\text { carbamate }\end{array}$ & & $\begin{array}{l}\text { UV light } \\
(\lambda=300 \mathrm{~nm})\end{array}$ & Primary amine & [61] \\
\hline $\begin{array}{l}\text { Hemiacetal } \\
\text { ester }\end{array}$ & & TFA & Carboxylic acid & [62] \\
\hline Acetal & & TFA & $\begin{array}{c}{ }_{H}{ }^{-}{ }_{H}{ }^{H} \\
\text { Alcohol }\end{array}$ & [64] \\
\hline Acetal & & TFA & Aldehyde & [63] \\
\hline
\end{tabular}

4 Table 2. Reversible junctions used for the preparation of functionalized nanoporous 5 polymers.

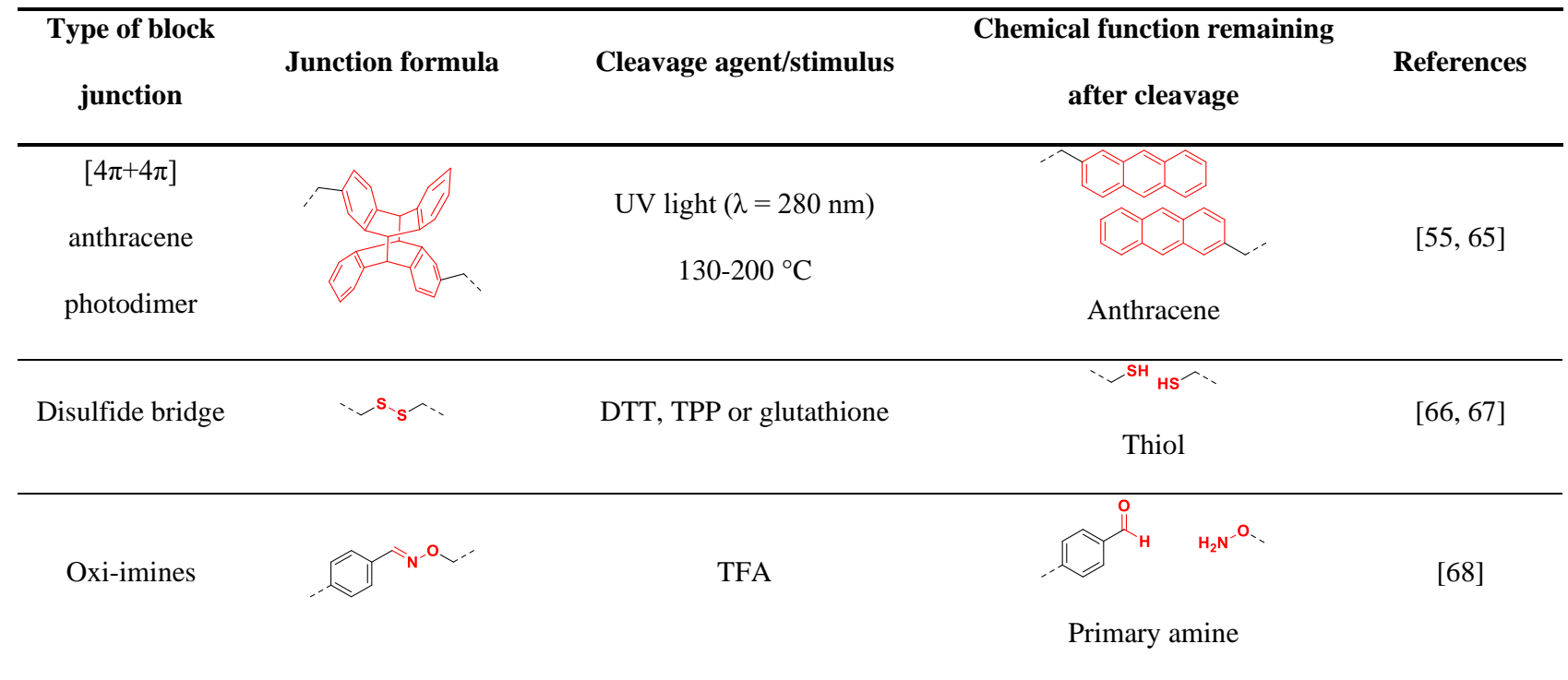




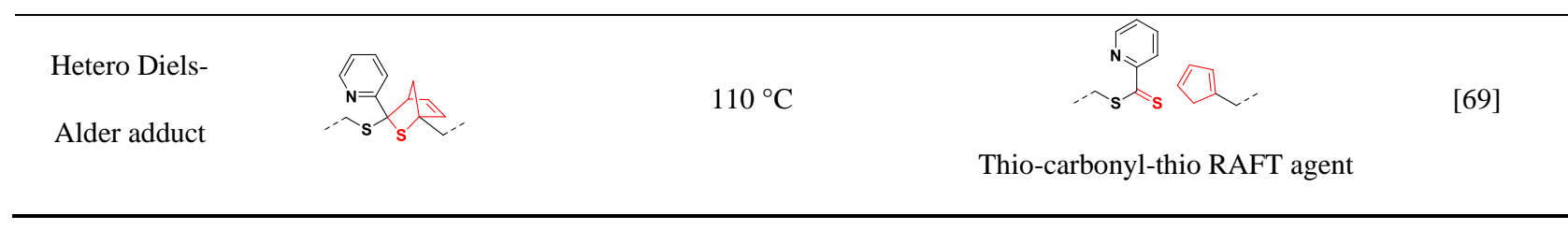

2 Finally, some polymeric materials develop intrinsic free volume that can be viewed as

3 micropores; this is the so-called intrinsic microporosity. Such micropore sizes notably allow

4 such types of material to be used for gas-related applications [75-77] especially for separation

5 sciences, gas storage or heterogeneous catalysis in the gaseous phase. Only monomers that

6 offer a good rigidity to the polymer network can prevent them from pore collapse and enable

7 a permanent microporosity. Polymeric microporous polycyanurate [78], polyisocyanurate

8 [79], polyurethane [80], polytriazine [54] (Fig. 3B), based on Tröger's base [81] or porous

9 aromatics frameworks $[82,83]$ can be found among such innovative materials. 
1 Table 3. Supramolecular junctions used for the preparation of functionalized nanoporous 2 polymers.

\begin{tabular}{cccc}
\hline $\begin{array}{c}\text { Type of block } \\
\text { junction }\end{array}$ & Junction formula & Cleavage agent & Chemical function remaining after \\
References
\end{tabular}

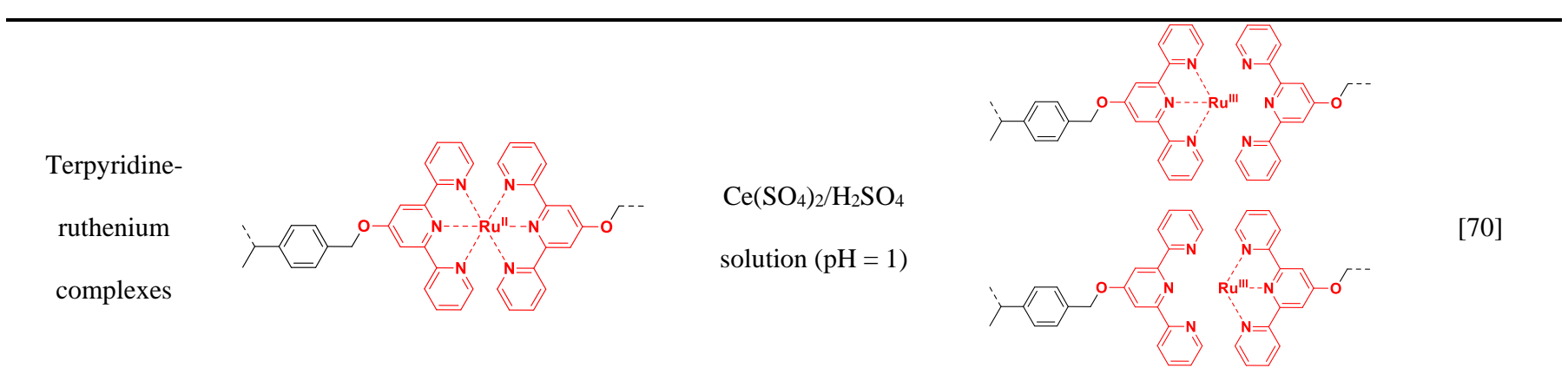

Terpyridine ligand

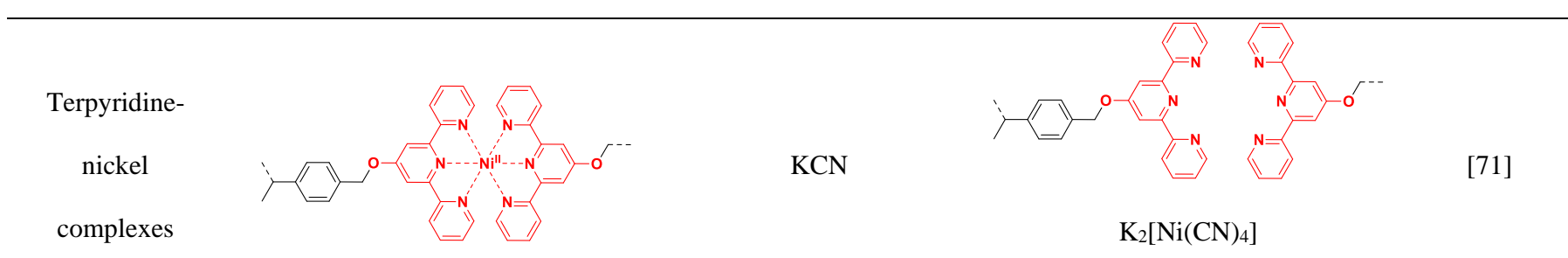

Terpyridine ligand

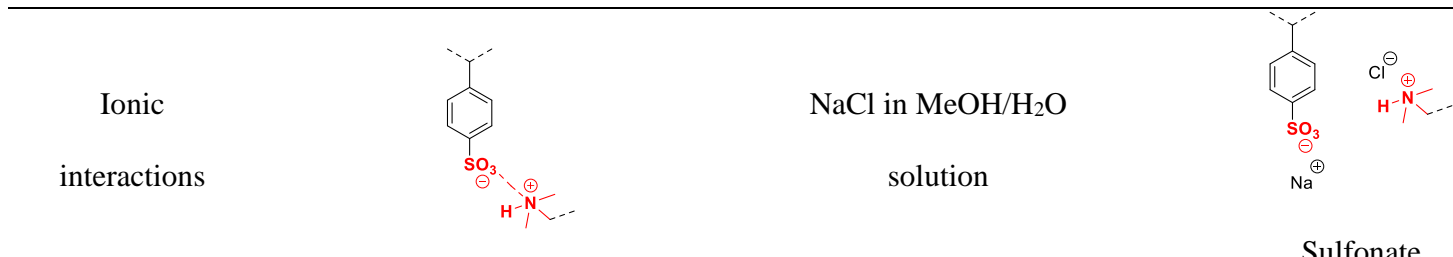

Sulfonate

Hydrogen bonds




\subsection{Biporous polymers}

Biporous materials have gained a tremendous interest within the last decades in different research area, such as civil engineering, tissue engineering or even drug delivery. Scientists are now able to prepare porous polymers possessing at least two distinct levels of porosity. Several methods have been so far developed to prepare biporous materials, including rapid prototyping (also called solid free-form fabrication or additive manufacturing) which is undergone by $3 \mathrm{D}$ printing [84], gas foaming [85], temperature-induced phase separation (TIPS) [86], the polyHIPE technique or the double porogen templating approach. Due to purpose considerations, this part will essentially focus on electropsun materials, polyHIPEs, and doubly porous materials derived from the double porogen templating approach, as these three strategies were recently implemented in the literature for the preparation of hybrid polymer-based materials dedicated to supported catalysis.

Closely related to the use of a 3-D printer (i.e. rapid prototyping) for constructing biporous materials, electrospinning is a powerful technique that allows for the formation of highly porous scaffolds from solutions of polymeric materials [87]. The electrospinning process was patented by Anton Formhals in 1934 [88], and it was intensively developed by Reneker's research group [89, 90] in the 1990's and 2000's with the emergency of nanotechnologies. Electrospun materials are prepared by applying a high voltage electrostatic field (usually in the $10-30 \mathrm{kV}$ range) between a syringe containing a viscous polymeric solution and a collector for the deposition of polymeric fibers. Due to the fiber packing, pores with a wide pore size distribution are generated between fibers, thus allowing for the production of macroporous materials with highly interconnected voids and a large ratio of surface area to volume [91]. Electrospun polymeric fibers present morphological similarities as natural collagen fibrils, and their morphologies can be easily tuned by varying different parameters, such as the voltage, the syringe needle-to-collector distance, the polymer solution 
1 flow rate, the solvent volatility and polarity, the polymer solution viscosity and conductivity,

2 etc. Therefore, choosing appropriate (co)solvents and electrospinning parameters are crucial

3 to finely control the porous features of resulting polymeric materials (Fig. 4A) [92].

4

Alternatively, polymerization of High Internal Phase Emulsions (HIPEs) is a

6 technique of choice to prepare biporous polymeric frameworks [93, 94]. Such materials were

7 first designed by Barby and Haq from Unilever in the early 1980's [95]. In this patent, the

8 authors reported on the preparation of a biporous polymer network obtained after the

9 polymerization of a high internal phase emulsion, the porous polymer being subsequently

10 called polyHIPE. In such polyHIPE-based scaffolds, the higher porosity level arises from

11 drops of the discontinuous phase of the emulsion, while the lower one originates from the

12 interconnections between adjacent pores. PolyHIPEs can be prepared from water-in-oil (w/o)

13 [96], oil-in-water (o/w) [97] emulsions or from emulsified biphasic systems constituted by

14 two immiscible liquids [98] in the presence of surfactants that help to the emulsion

15 stabilization. Due to monomers and cross-linkers remaining in the external continuous phase,

16 w/o emulsions are appropriate to yield hydrophobic polymers such as styrenic polyHIPEs [99]

17 while o/w emulsions are suitable for the production of more hydrophilic polymers (Fig. 4B)

18 [97]. 

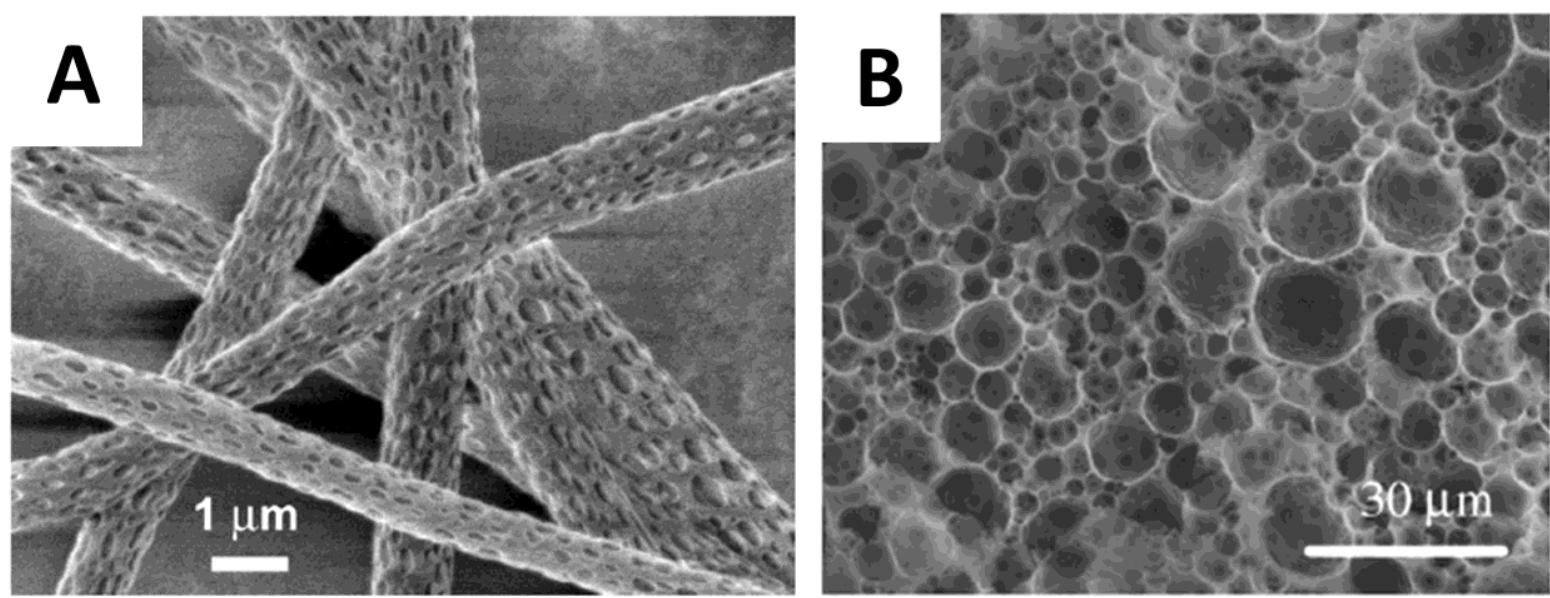

2 Fig. 4. Examples of biporous polymeric materials observed by SEM. (A) Biporous polymeric 3 material generated by a combination of electrospinning and particle leaching. [92], Copyright 42001 (Reproduced with permission from Wiley-VCH publishers). (B) Biporous polymeric 5 material obtained via high internal phase emulsion. [100], Copyright 2007 (Reproduced with 6 permission from Elsevier Ltd.). 

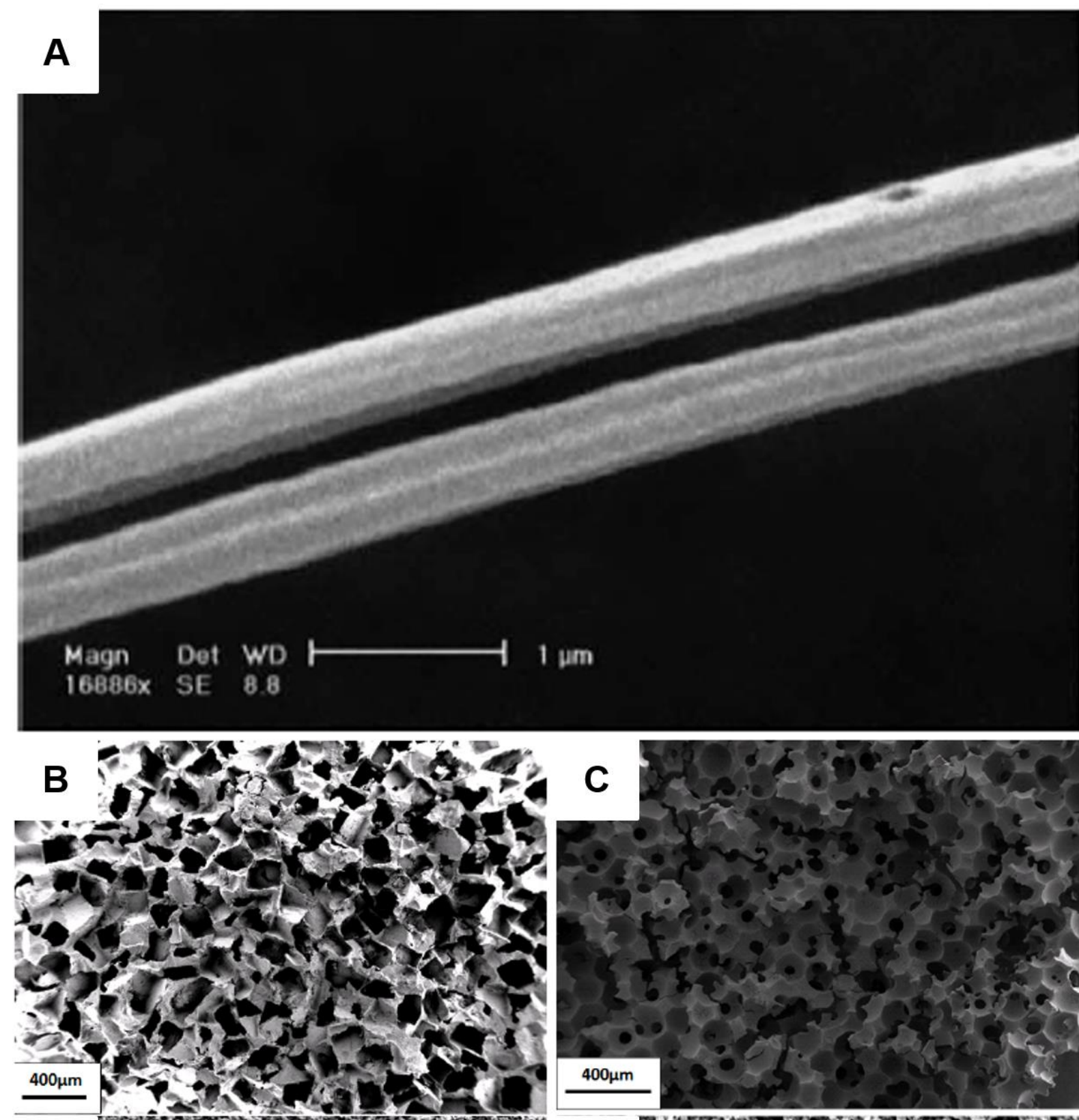

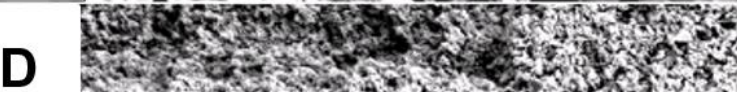

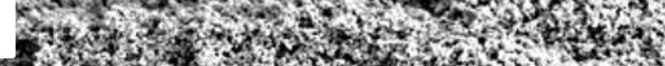
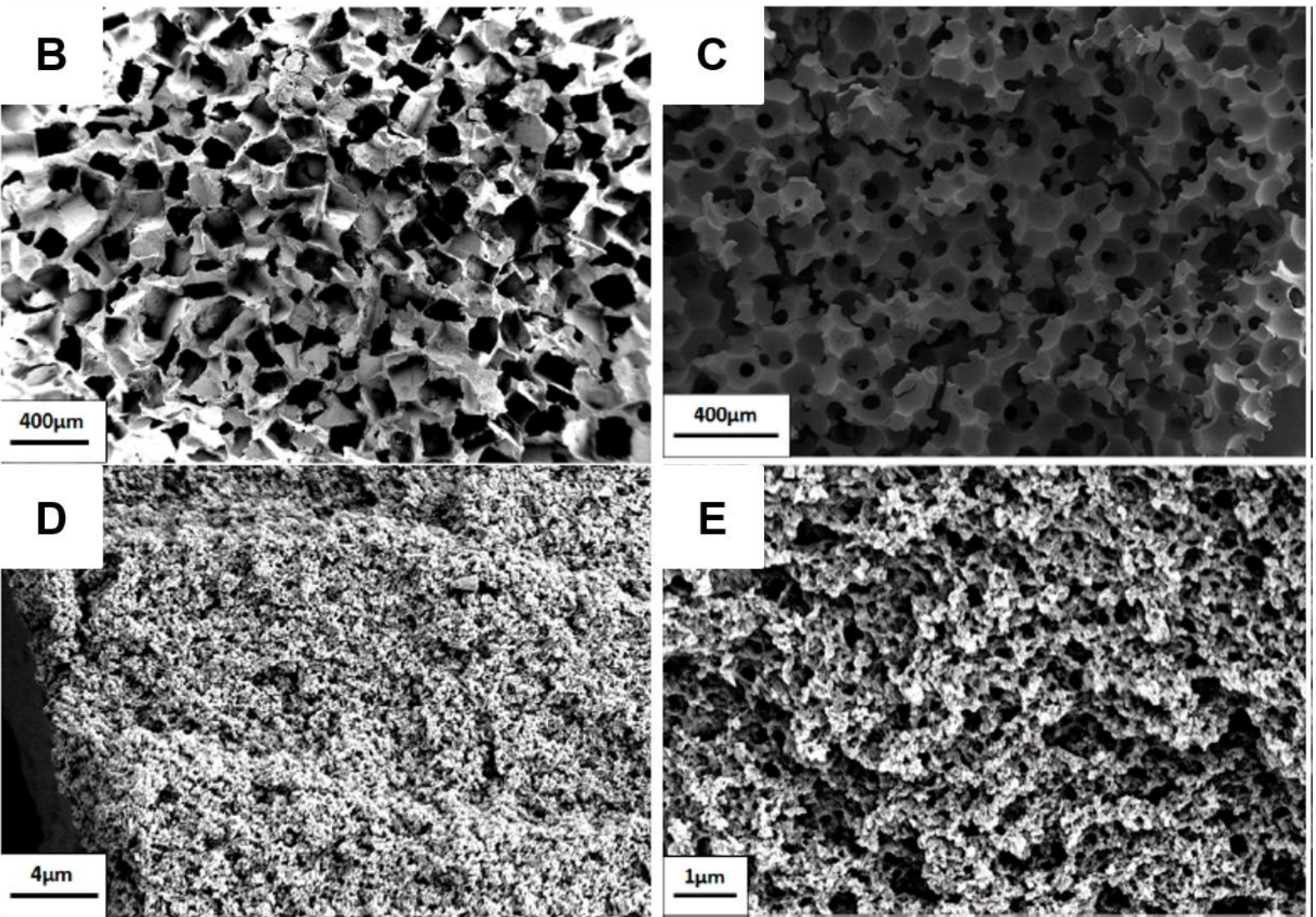

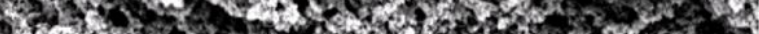

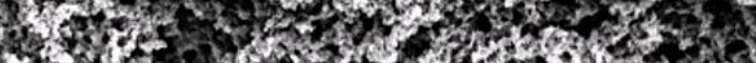

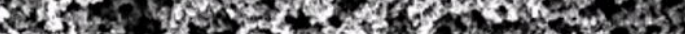

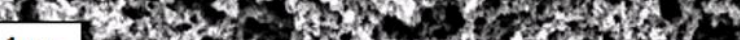
$1 \mu \mathrm{m}$ ora

2 Fig. 5. Examples of doubly porous materials obtained through the double porogen approach.

3 (A) Porous polyacrylonitrile prepared via a combination of electrospinning and $\mathrm{CaCO}_{3}$

4 particle leaching. [101], Copyright 2013 (Reproduced with permission from Wiley-VCH 
1 publishers). Biporous poly(hydroxyethyl methacrylate) frameworks obtained via a

2 combination of $\mathrm{NaCl}$ particle leaching concomitant to the use of a porogenic solvent (B), (D)

3 or via extraction of PMMA beads and a porogenic solvent (C), (E). [102], Copyright 2015.

4 Reproduced with permission from Springer.

Last but not least, the double porogen templating approach consists in using two different types of porogenic agents, i.e. one for the generation of pores within the micrometer range and the other one to obtain pores within the nanometer range. For instance, the use of electrospinning and particle leaching [101] (Fig. 5A) allowed for the preparation of materials with a macroporosity generated by the fibers organization and a nanoporosity revealed by 11 calcium carbonate particle leaching using 1, 3, and 5\% v/v of $\mathrm{HCl}$ aqueous solution, increasing the specific surface area of the porous scaffolds. Another interesting approach using two different porogens was described by Ly et al. Poly(HEMA-co-EGDMA) monoliths were synthetized using macroporogenic agents consisting of fused PMMA beads [102] or $\mathrm{NaCl}$ particles [102-106] and different porogenic solvents (Fig. 5B,C) [103]. The fused macroporogens allow for the pores generated after particle leaching to be interconnected,

17 while the porogenic solvent gives rise to a lower porosity level, thus enhancing the specific 18 surface area of the resulting doubly porous materials. Different experimental conditions such as the particle sintering conditions (Spark Plasma Sintering vs. vacuum oven), the particle morphology (spherical vs. cubic) as well as the porogenic solvent nature were carefully

21 investigated. Such studies have led to optimized materials on which were immobilized gold nanoparticles, thus leading to porous hybrid materials meant for heterogeneous supported catalysis $[105,106]$. 


\subsection{Characterization techniques of porous materials}

Different techniques have been so far developed for the fine characterization of porous materials. In this way, critical information, including pore size, pore size distribution, pore connectivity (open vs. closed, i.e. presence or absence of interconnections between adjacent pores), and specific surface area, can be accurately determined using complementary physicochemical techniques in the laboratory.

Two different techniques are mainly used to determine the pore size of porous polymeric materials. Such techniques rely on the type of porous materials under investigation. Mercury intrusion porosimetry (also shortened as MIP, Table 4) is a specific technique consisting in intruding a non-wetting liquid, i.e. mercury, into a porous sample placed within a penetrometer. Upon applying an increasing pressure, mercury is forced to intrude into the pores of the material [107]. Mercury does not wet materials, and so it will not penetrate pores by capillary action, excepted if it is forced to do so by applying the said pressure. The pore size can then be determined by correlating the pressure required for mercury intrusion into the pores to the pore size via the Washburn equation (Equation 1) [108]:

$$
P=\frac{-4 \gamma \cos \theta}{D}
$$

where $P$ is the pressure applied for the mercury intrusion, $\gamma$ is the mercury surface tension, $\theta$ is the contact angle between the mercury and the pore wall, and $D$ stands for the diameter of the pore being intruded.

It is noteworthy that the pores are supposed to by cylindrical in this equation, while most of the real porosity is not. As said before, for MIP analyses, the porosimeter apply a pressure to force mercury intruding the pores, and the Washburn equation allows for determining the pore diameter [109]. Applying an increasing pressure indeed pushes known amounts of mercury into the porosity of the material, and it thus allows for determining the pore volume for a precise pore size. Additionally, knowing the distribution of the pore volume 
1 with respect to its pore size provides the pore size distribution [110]. However, this technique

2 has some limitations especially regarding pore sizes in the nanometer range.

4 more appropriate, especially for accuracy reasons [111]. Gas sorption measurements can use

5 different gases: mostly $\mathrm{N}_{2}$ [112] is used, but $\mathrm{CO}_{2}$ [113] or $\mathrm{Kr}$ [114] can also be employed at a

6 precise temperature to obtain isotherms. Gas sorption porosimetry is now routinely used to

7 determine the specific surface area of porous materials, using the Brunauer-Emmett-Teller

8 (BET) method [115], whose equation is given below (Equation 2):

$$
\frac{P}{n^{a}\left(P_{0}-P\right)}=\frac{1}{n_{m}^{a} C}+\frac{(C-1)}{n_{m}^{a} C} \times \frac{P}{P_{0}}
$$

10 where $n^{a}$ is the gas amount adsorbed at the relative pressure $\frac{P}{P_{0}}, n_{m}^{a}$ is the monolayer capacity,

11 and $C$ is a constant, which is function of the isotherm shape. According to this equation, a 12 linear relation exists between $\frac{P}{n^{a}\left(P_{0}-P\right)}$ and $\frac{P}{P_{0}}$ so it is possible to determine $n_{m}^{a}$, thus leading to

\section{3 (Equation 3):}

$$
A(B E T)=n_{m}^{a} \times L \times a_{m}
$$

where $A(B E T)$ is the specific surface area, $L$ the Avogadro constant, and $a_{m}$ the average area occupied by each adsorbed molecule in the complete monolayer (i.e. the molecular crosssectional area).

Gas sorption measurements can also give pore sizes for porous materials exhibiting a porosity from 2 to $300 \mathrm{~nm}$ using the so-called Barrett-Joyner-Halenda (BJH) method (Table 4) [116]. Similarly to MIP, this calculation method leads to a pore size distribution, but it is

21 limited for materials exhibiting pores higher than $0.1 \mu \mathrm{m}$. Alternatively, a less widespread characterization technique can be used for the porosity characterization of mesoporous materials, namely thermoporometry (Table 4), based 
1 on differential scanning calorimetry (DSC) [117]. This technique relies on the Gibbs-

2 Thomson equation (Equation 4) [113]:

3

4 where $D_{p}$ is the pore diameter, $A$ and $B$ are constants depending on saturating solvent, pore on the use of nuclear magnetic resonance (NMR) [121].

geometry and measurements on cooling or heating, $T_{m}$ and $T_{m 0}$ are the melting temperatures of confined liquid and bulk liquid, respectively.

If a porous material is filled with a liquid, and then the latter is frozen, the melting temperature $T_{\mathrm{m}}$ of the liquid will not be the same for that confined in the pores and that in the bulk. $T_{\mathrm{m}}$ for the liquid in the pores will be lower, and the difference between $T_{\mathrm{m}}$ and the bulk liquid melting temperature provides the pore diameter according to Equation 4. Besides, comparing data from freezing and melting phenomena leads to precious information regarding the pore shape. The limitation of this technique is due to its principle: if the pore size is too high, the liquid confined into the pores will act as a bulk liquid. Therefore, the melting peak of the confined liquid will be hidden into the profile of the bulk liquid melting peak and no differences will be observable. However, DSC-based thermoporometry has been proved to be effective using various solvents, like water [118], benzene [118], cyclohexane [119] or

$$
D_{p}=2\left(A+\frac{B}{T_{m}-T_{m 0}}\right)
$$


1 Table 4. Common techniques used for the characterization of pore diameter in porous 2 polymers and their characteristics.

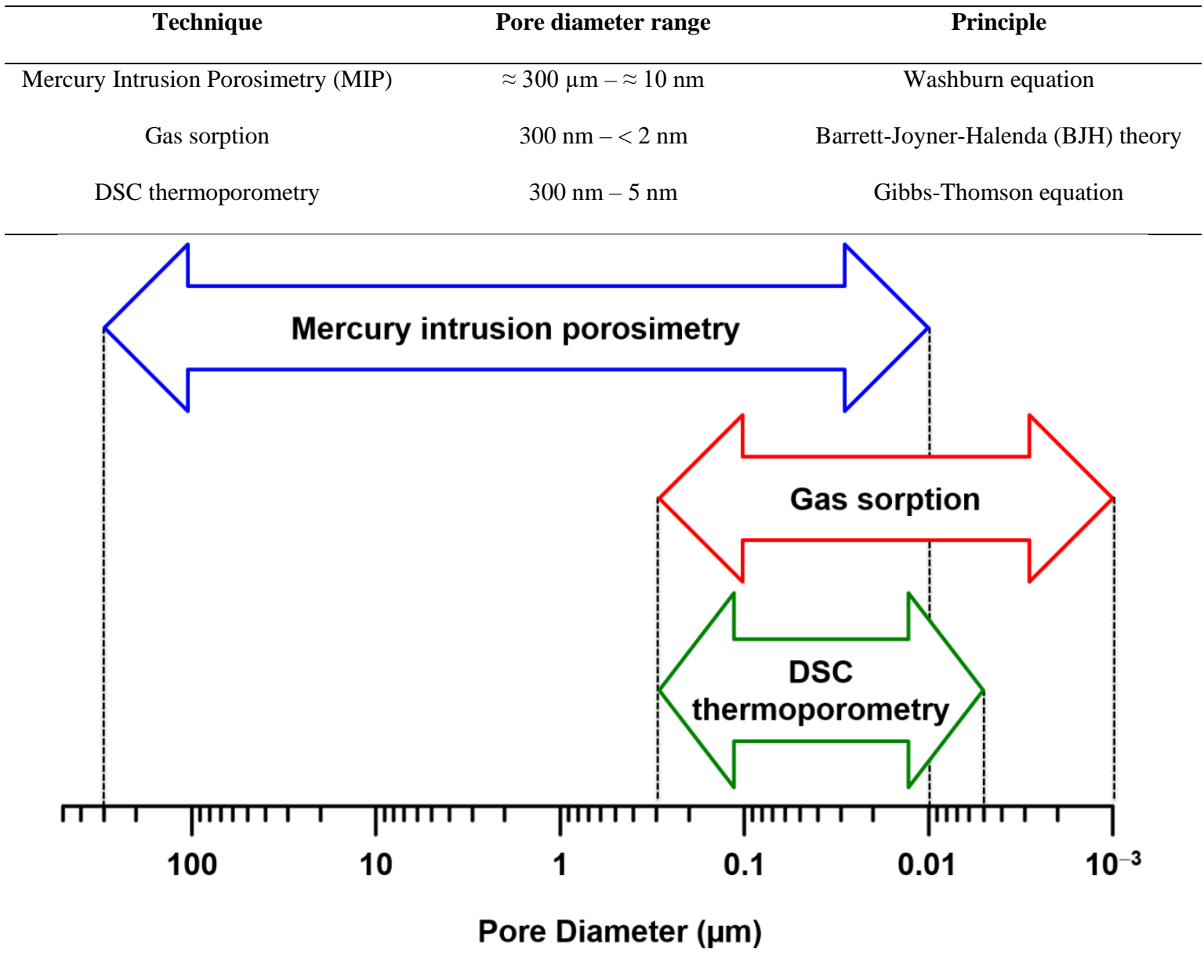

3

Finally, pycnometry can be used to determine an "apparent density" (more precisely a volume) of a porous solid, which is defined as the ratio between its mass and the total volume enclosed by an envelope of fluid. Pycnometry mostly uses gases, such as helium (He), but it can also be achieved with liquids, such as water or xylene. A typical pycnometer consists of two sealed chambers connected between them by a valve. The first chamber is used as a reference and the second one holds the sample. The sample chamber is filled with the fluid, while the other one is still under vacuum. Then, the valve is opened and the fluid is allowed to expand into the second chamber at a precise temperature while the pressure is measured, thus giving the volume of the sample $V_{S}$, i.e. the open porosity volume using the Boyle-Mariotte law (Equation 5) [122]: 


$$
V_{S}=V_{C}-\frac{V_{r}}{1-\frac{P_{1}}{P_{2}}}
$$

2 where $V_{C}$ is the volume of the empty sample chamber, $V_{r}$ is the volume of the second

3 chamber, $P_{1}$ is the first pressure in the sample chamber and $P_{2}$ is the pressure after expansion

4 into the combined volume of the chambers.

It is important to notice that pycnometry gives the volume of the open porosity. In the case of a closed porosity in the sample, the density will be an effective one. To give access to the closed porosity, two measurements are required: one with a porous system and another with a bulk system. The comparison between both gives access to the volume of the closed porosity [123]. This method has been extended to other porous polymeric systems to enable the characterization of polymer gels for instance.

3 Application of metallic nanoparticle immobilized on porous polymers as supported catalysts

\subsection{Key features of nanoparticles}

Nanoparticles have been widely used as catalysts in the past decade, as they offer large surface area and consequently enhanced catalytic activity. Well-documented reviews discussing both synthesis and catalysis aspects can be found in the literature $[124,125]$ and, in most cases, these reviews focused on a sole metal type. The reader is kindly referred to the reviews by Takale et al. [126] or Daniel \& Astruc [127] for critical discussion about gold nanoparticles (Au NPs) and their catalytic uses, while Gawande et al. [128] and Ranu et al. [129] focused on copper nanoparticles (Cu NPs). Chen \& Holt-Hindle [130] and Astruc [131] detailed platinum (Pt NPs), and palladium (Pd NPs) nanoparticles, respectively. Herein, we purposely restricted the discussion to the cases of metal NPs supported on organic porous polymers for catalysis in organic chemistry. Although supported catalysts have been much 
1 supports [129]. More specifically, one may cite the comprehensive survey by Corma and

2 Garcia [130] who exclusively summarized recent trends in nanogold supported onto inorganic

3 supports as catalysts for organic synthesis as well as that from Campelo and coworkers [131]

4 describing the synthesis and applications of nanoparticles of various metals.

Regarding the immobilization of nanoparticles onto solid supports, two main ways

6 have been reported to date in the literature, hereafter referred to as ex-situ and in-situ ways

7 (Fig. 6). It is crucial to mention that in order to achieve robust surface anchoring of metal nanoparticles (MNPs), the supports may preferably bear accessible chemical moieties able to induce specific interactions with the metal in its ionic or reduced forms. Amines, thiols, cyanos, and carboxylic acids are representative examples ensuring strong interactions with

11 metals, such as gold, copper, palladium. In some cases, the interactions can occur between the 12 chemical units attached on solid surface and the stabilizing agent decorating the NP surface. Porous polymers with chelating ability can be easily designed using monomers incorporating 14 functional side groups that may act as either chelation sites (for example 2(dimethylamino)ethyl methacrylate) or reactive sites for post-polymerization

16 functionalization. In the latter case, one may cite GMA, 4-VBC, NAS, or GCMA. the pore surface. Well-established methods were typically applied for the synthesis of metal colloids. In a further step, the NPs are immobilized onto the solid supports. A major advantage of the $e x$-situ approach is that it offers the possibility to use commercially available nanoparticles. Although it makes easier the whole synthesis process and provides fine control over the size distribution and colloidal stability of the NPs, it may be restrictive in terms of available size and shape. 

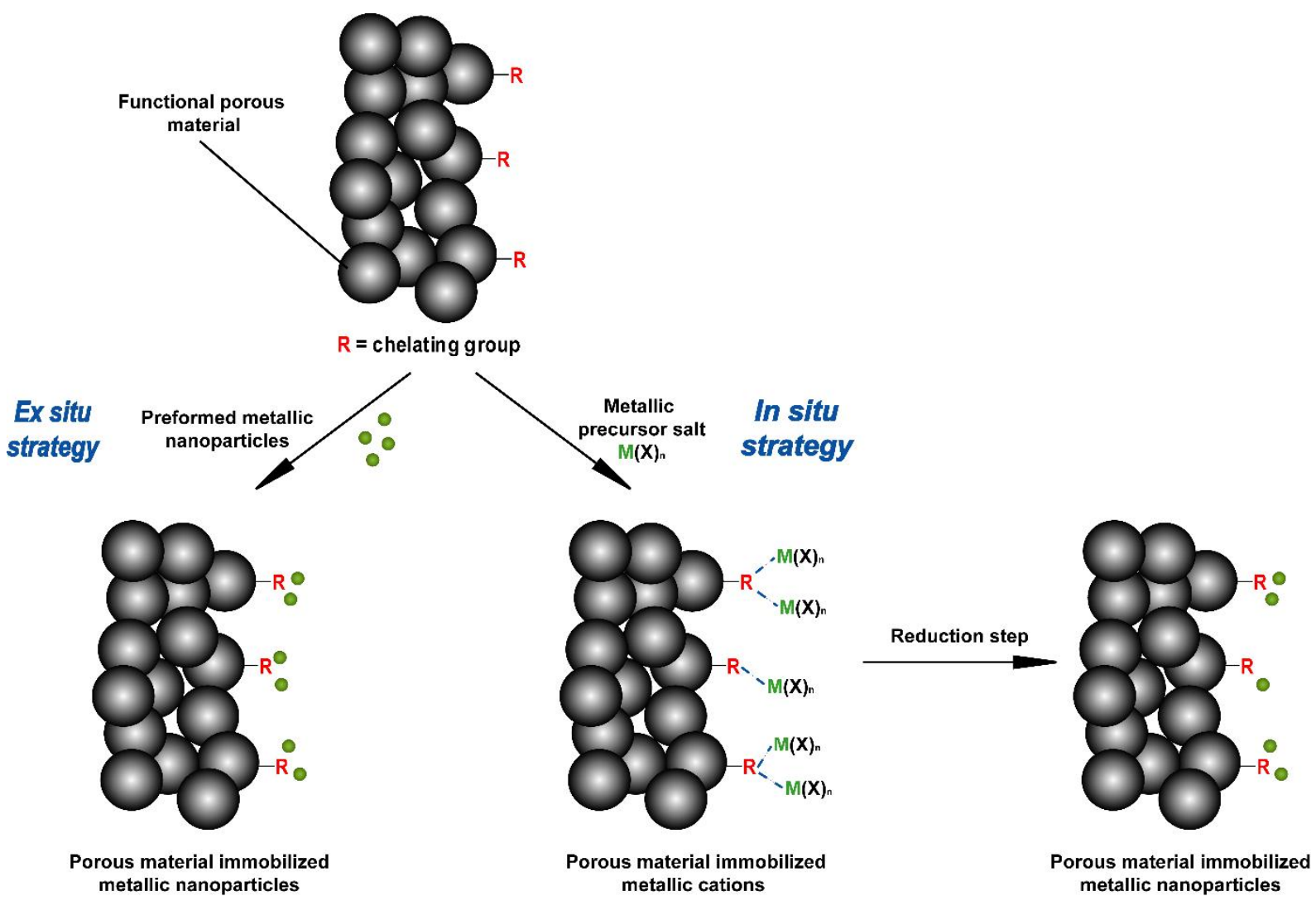

2 Fig. 6. Scheme representing the two main ways, namely ex situ and in situ ways, for the 3 immobilization of nanoparticles onto a porous support.

In contrast, the in-situ way implies the generation of the NPs in presence of the solid supports and is thus a deposition precipitation process [132]. First, the support is immerged into a solution containing the salt of the metal of interest for impregnation purpose. Then, the metal is reduced to its zero state through a reduction step. Several reducing agents are

9 routinely used in organic synthesis (Table 5) and can be also envisaged for metal reduction, like $\mathrm{NaBH}_{4}[133,134]$, citrates $[135,136]$ (in the so-called Turkevitch process), hydrazine

11 [137] or even $\mathrm{H}_{2}[138,139]$. The choice of the reducing agent will depend on the size and

12 shape desired for the NPs and is crucial to achieve controlled synthesis. Indeed, depending on 13 the metal - reducing agent pair, various levels of control on the shape, size and surface 14 distribution will be obtained. Other important parameters are the strength of the interaction 
1 between metal ions and the chemical groups at the surface of the support as well as the

2 reducing agent/salt precursor ratio.

4 Table 5. Examples of common reducing agents used for the preparation of nanoparticles.

5 Typical conditions for reduction are also provided.

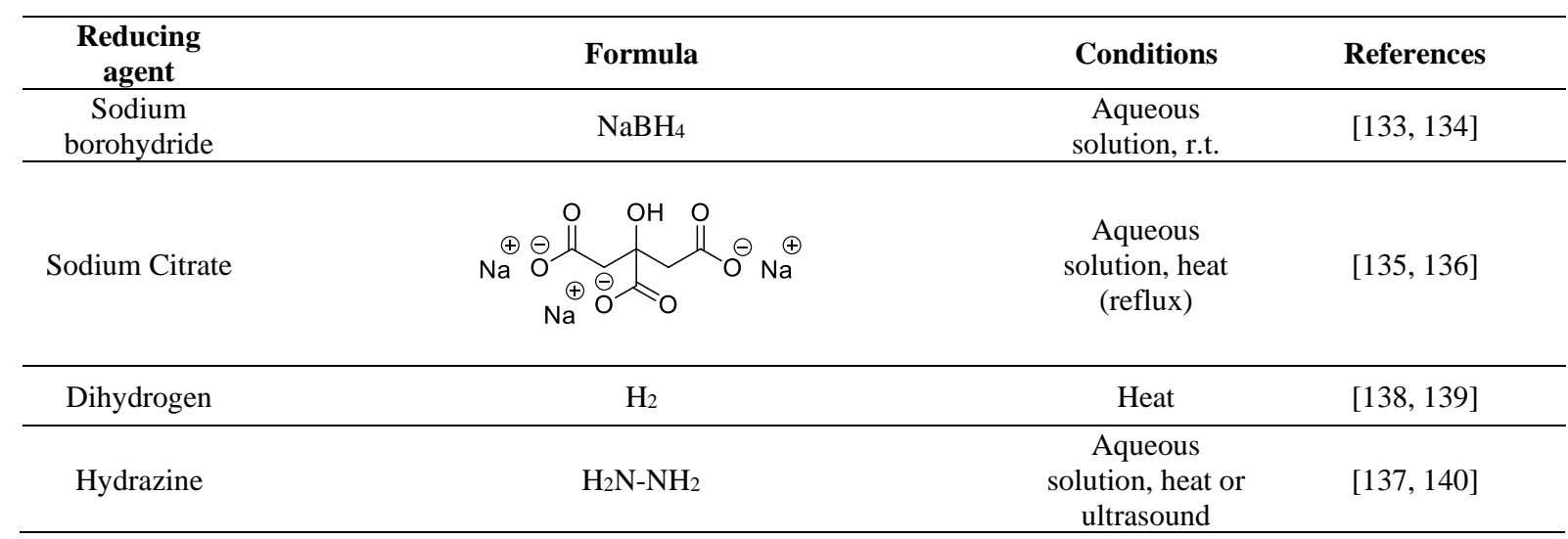

6 required after several catalytic cycles.

Although easy to implement, successful surface nanostructuration of porous polymers with nanoparticles implies that the NPs are strongly anchored so that leaching phenomenon does not occur. Indeed, the latter is detrimental to product purity as the presence of metal, even at the trace levels, may induce toxicity to human beings. As such, the selection of the chelating moiety is highly important and must be rationalized with respect to the nature of the metal and stabilizing agents. Generally speaking, the stronger the interaction between the support and the catalyst, the lower the possibility of leaching. One should of course keep in mind that the conditions for the immobilization of the NPs may differ significantly from the conditions for the catalysis applications. Changes such as solvent, $\mathrm{pH}$ and temperature may affect the strength of the chelation. Finally, the supported catalyst may be in contact with a variety of chemicals in the course of the catalytic cycles that may pollute the catalyst surface and eventually affect the turnover number and frequency. Thus, regeneration is usually 


\section{$1 \quad 3.2 \quad$ Nanoparticles supported by macroporous polymers}

Supported catalysts have not been widely described in the literature and this is

3 particularly true in the case of porous polymer-based supports. Herein, we purposely opted for

4 a discussion on the basis of the type of polymeric support rather than the type of the catalyzed

5 reaction or nature of the metal NP (Table 6).

6

7 Table 6. Example of catalyzed reactions performed using metal nanoparticles supported on 8 polymers.

\begin{tabular}{|c|c|c|c|c|c|}
\hline Name of the reaction & Reactant(s) & $\begin{array}{c}\text { General } \\
\text { conditions }\end{array}$ & Catalyst & Product(s) & References \\
\hline Nitroarenes reduction & $\mathbf{R}$ & $\begin{array}{c}\mathrm{H}_{2} \mathrm{O}, \mathrm{NaBH}_{4}, \\
\text { r.t. }\end{array}$ & $\begin{array}{c}\mathrm{Au}, \mathrm{Ag}, \\
\mathrm{Cu}, \mathrm{Pt} \\
\mathrm{Pd}\end{array}$ & $\mathrm{NH}_{2}$ & $\begin{array}{c}{[31,63,66} \\
105,106, \\
140-148]\end{array}$ \\
\hline $\begin{array}{l}\text { Mizoroki-Heck } \\
\text { coupling }\end{array}$ & $\mathbf{X}=\mathbf{I}, \mathbf{B r}$ & $\begin{array}{l}\text { DMF, Base, } \\
\approx 100{ }^{\circ} \mathrm{C}\end{array}$ & $\mathrm{Pd}$ & & [149-151] \\
\hline $\begin{array}{l}\text { Suzuki-Miyaura } \\
\text { coupling }\end{array}$ & $\mathbf{X}=\mathbf{I}, \mathbf{B r}$ & $\begin{array}{l}\text { Ethanol or } \\
\text { DMF, Base, } \\
\quad \approx 100{ }^{\circ} \mathrm{C}\end{array}$ & $\mathrm{Pd}$ & & $\begin{array}{c}{[145,150-} \\
157]\end{array}$ \\
\hline Boronic homocoupling & 'он & $\begin{array}{l}\text { Ethanol, Base, } \\
\quad \approx 65^{\circ} \mathrm{C}\end{array}$ & $\mathrm{Au}$ & & {$[63]$} \\
\hline Sonogashira coupling & $\mathbf{X}=\mathbf{I}, \mathbf{B r}$ & $\begin{array}{l}\mathrm{H}_{2} \mathrm{O} \text { and THF, } \\
\text { Base, } \approx 50^{\circ} \mathrm{C}\end{array}$ & $\mathrm{Pd}$ & & {$[151,157]$} \\
\hline Hydrosilylation & 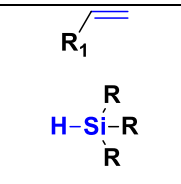 & $\begin{array}{c}n \text {-hexane, } 45 \\
{ }^{\circ} \mathrm{C}\end{array}$ & $\mathrm{Pt}$ & & {$[158]$} \\
\hline Eosin $\mathrm{Y}$ reduction & $\mathrm{Br}$ & $\begin{array}{l}\mathrm{H}_{2} \mathrm{O}, \mathrm{NaBH}_{4}, \\
\text { r.t. }\end{array}$ & $\mathrm{Au}$ & $\mathrm{Br}$ & {$[100,159]$} \\
\hline $\begin{array}{c}\text { Reduction of } \\
\text { hexacyanoferrate(III) }\end{array}$ & $\mathrm{Fe}(\mathrm{CN}) 6^{3-}$ & $\begin{array}{l}\mathrm{H}_{2} \mathrm{O}, \mathrm{NaBH}_{4} \text { or } \\
\text { thiosulfate, r.t. }\end{array}$ & $\begin{array}{l}\mathrm{Au} \text { or } \\
\mathrm{Pd} / \mathrm{Pt}\end{array}$ & $\mathrm{Fe}(\mathrm{CN}) 6^{4-}$ & {$[20,160]$} \\
\hline
\end{tabular}




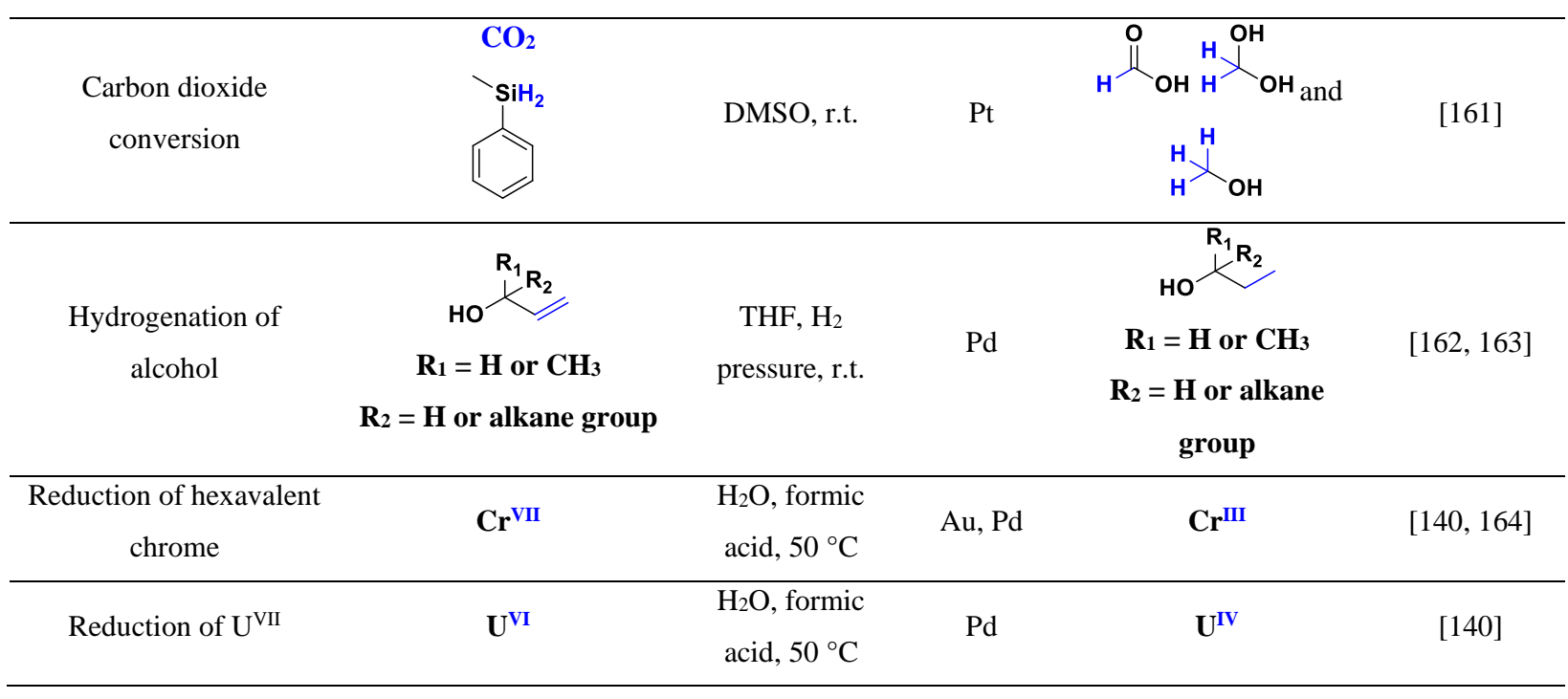

2 As discussed above, macroporous polymers are essentially generated using a solvent as a

3 porogen [16]. Using such a process, many examples focused on the synthesis of monolithic

4 polymers within microchannels. The as-generated monolithic-based microsystems can be

5 used after immobilization of metal nanoparticles either as sorbents for solid phase extraction

6 or separation purposes or as microreactors for flow through catalysis. One may briefly

7 mention papers from teams of Svec, Buchmeiser, Connolly or Carbonnier who have extended

8 the concept of metal nanoparticules decorating monoliths as chromatographic microcolumns

9 to supported catalysts in continuous flow microreactors [18, 165-167]. In their pioneering

10 work, Nikbin, Ladlow \& Ley described in 2007 the synthesis of a vinylbenzyl chloride-based

11 column and its subsequent functionalization with triethylamine to generate ammonium groups

12 at the pore surface [149]. The porous features of the obtained monolithic column were

13 investigated both by MIP and BET techniques, showing a median pore size of $3.15 \mu \mathrm{m}$ and a

14 surface area of about $5 \mathrm{~m}^{2} \cdot \mathrm{g}^{-1}$. The available surface groups were used to immobilize Pd NPs

15 onto the pore surface through a deposition precipitation process. First, the porous polymer

16 was flushed with an aqueous solution of $\mathrm{Na}_{2} \mathrm{PdCl}_{4}(20 \mathrm{mM})$ followed by in-situ reduction of

17 the surface immobilized Pd ions with sodium borohydride. The reactor was used for the

18 Mizoroki-Heck reaction of different iodobenzyls with styrene and acrylate derivatives 
1 providing high yields above $80 \%$ (Table 7). The authors conclusively demonstrated that flow-

2 through processes were superior to batch reaction, notably because of the possibility of 3 processes automation.

4 The Buchmeiser group worked on the preparation of porous materials into chromatographic

5 columns based on Ring Opening Metathesis Polymerization (ROMP), and suggested several

6 potential applications. Restricting the discussion to supported catalysis, they developed

7 monoliths bearing platinum (Fig. 7A) or palladium-based nanoparticles, obtained through the

8 in-situ reduction of the corresponding salts, and proved their efficiency for several catalytic

9 reactions like hydrosilylation [158] and carbon dioxide conversion [161] or Mizoroki-Heck

10 [150], Suzuki-Miyaura [150] (Table 7) and Sonogashira [157] (Table 7). Of particular

11 interest, the authors reported high TurnOver Numbers (TONs, representing the number of

12 moles of reactants that a mole of catalyst can convert before decrease in the catalyst activity).

13 TONs values higher than 600000 were reported for the hydrosilylation reaction. 

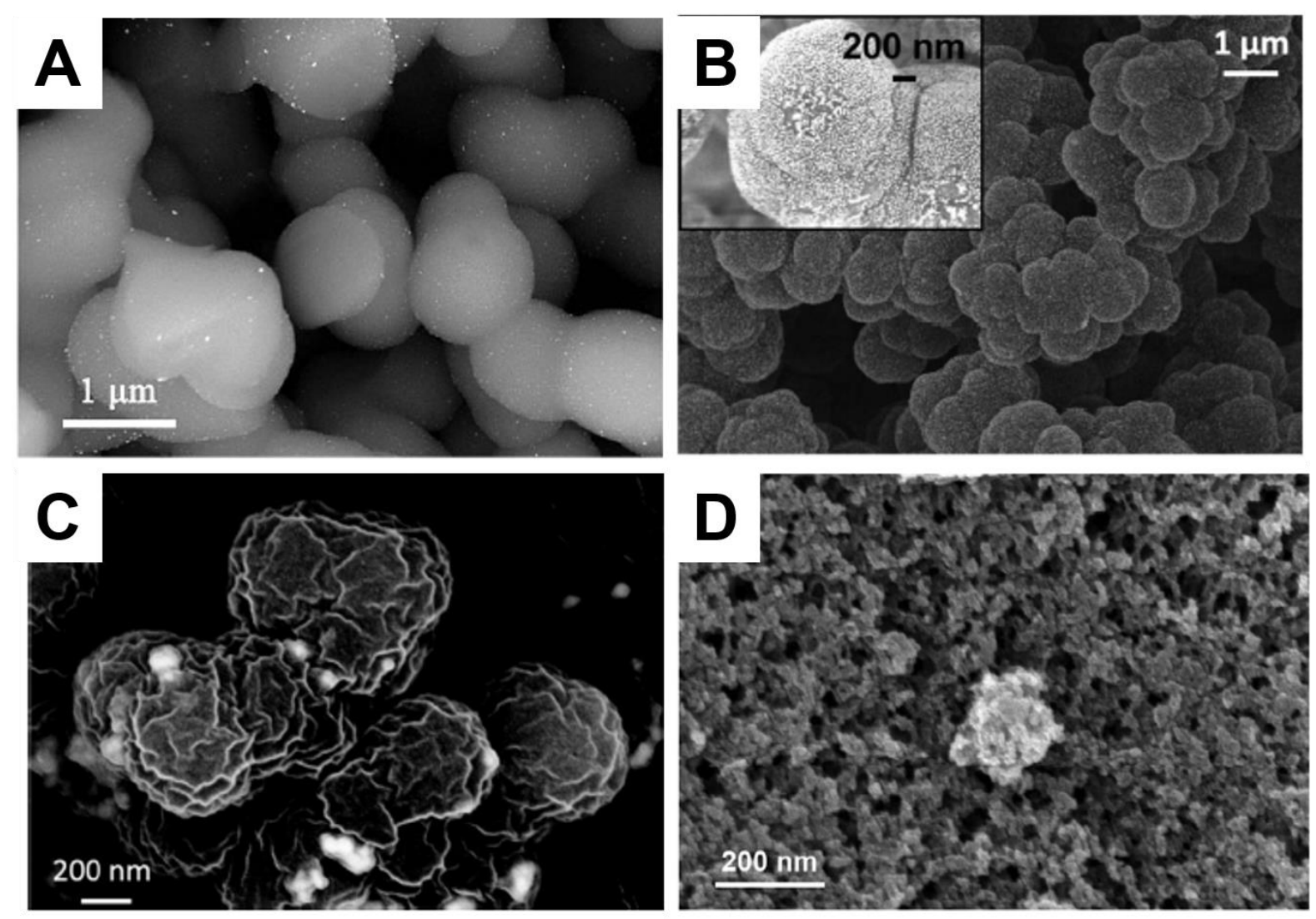

2 Fig. 7. Examples of macroporous polymeric materials bearing metallic nanoparticles. (A) in-

3 situ generated Pt NPs onto a ROMP-generated-matrix capillary. [158], Copyright 2012

4 (Reproduced with permission from the Royal Society of Chemistry). (B) ex-situ generated Au

5 NPs onto a NAS-matrix capillary. [146], Copyright 2017 (Reproduced with permission from

6 the Royal Society of Chemistry). (C) ex-situ generated Cu NPs onto a NAS-matrix capillary.

7 [31], Copyright 2015 (Reproduced with permission from Elsevier Ltd.). (D) in-situ generated

8 Au NPs onto a DSDMA bulk monolith. [159], Copyright 2017 (Reproduced with permission

9 from Elsevier Ltd.).

11 Connolly's team used glycidyl methacrylate- and vinyl azlactone-based monoliths to anchor 12 as-prepared gold nanoparticles [160] as well as bimetallic platinum/palladium nanoflowers 13 [20]. In both cases, the NPs were synthetized ex-situ according to literature protocols, and 14 then flushed directly into polymer-filled capillaries or pipette-tips. Amine moieties were 15 grafted onto the polymeric surface using ethylenediamine and were used to anchor both types 16 of nanoparticles. The as-designed supported catalysts were used to reduce a ferric complex, 
1 hexacyanoferrate $\mathrm{Fe}(\mathrm{CN})_{6}{ }^{3-}$, into $\mathrm{Fe}(\mathrm{CN})_{6}{ }^{4-}$ using $\mathrm{NaBH}_{4}$ as a co-reagent. BET measurements

2 performed on the GMA- and vinyl azlactone-based monoliths bearing gold and bimetallic

3 nanoflowers showed a significant decrease in the surface area of the materials before and after

4 adsorption of preformed nanoobjects from 40 to $12 \mathrm{~m}^{2} \cdot \mathrm{g}^{-1}$. The authors explained these rather

5 surprising results by a potential clogging of the porosity by the adsorbed 20-nm sized

6 nanoflowers.

7

8 Table 7. Examples of C-C coupling reactions achieved using polymer-supported metal 9 nanoparticles. The reactions conditions and yields are also presented.

\begin{tabular}{|c|c|c|c|c|c|c|c|}
\hline \multicolumn{2}{|c|}{ 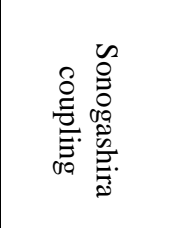 } & \multicolumn{2}{|c|}{ 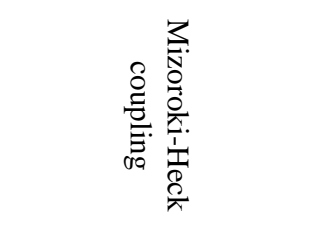 } & \multicolumn{3}{|c|}{ 竞 } & 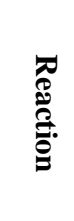 \\
\hline 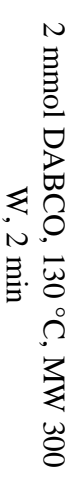 & 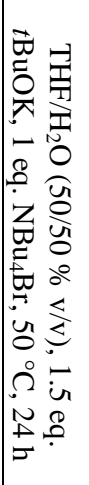 & 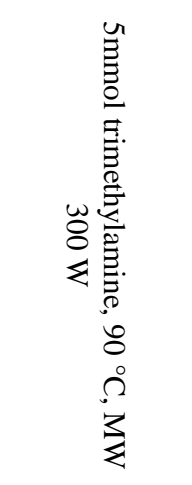 & 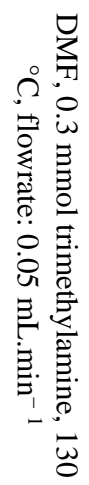 & 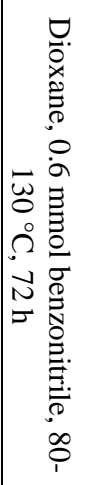 & 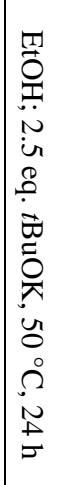 & 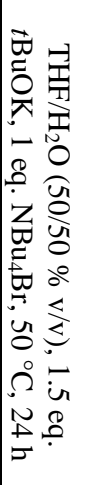 & 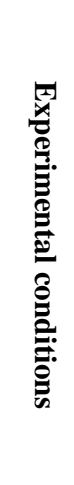 \\
\hline$\beth$ & $\check{2}$ & 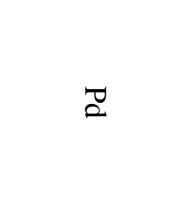 & $\Xi$ & 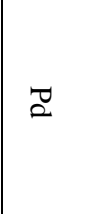 & $\check{\beth}$ & $\Xi$ & 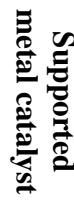 \\
\hline 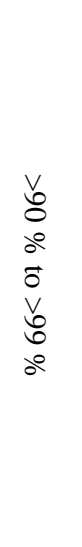 & 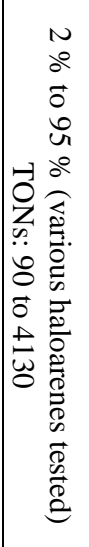 & 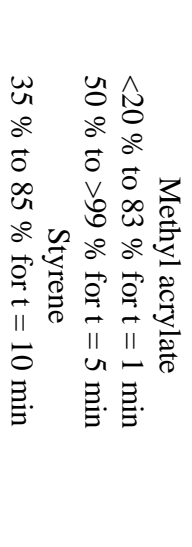 & 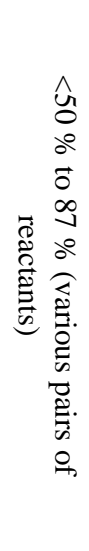 & 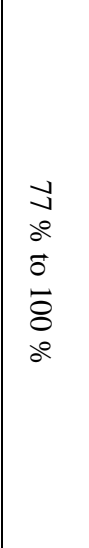 & $\begin{array}{l}2 \\
2 \\
29\end{array}$ & 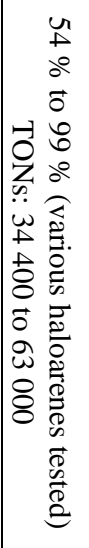 & $\frac{0}{2}$ \\
\hline
\end{tabular}




\begin{tabular}{|c|c|c|c|c|c|c|c|}
\hline$\overline{\bar{u}}$ & 窵 & 苞 & 胥 & $\overline{\breve{s}}$ & 忍 & $\overline{\tilde{\varrho}^{\prime}}$ & 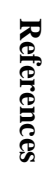 \\
\hline
\end{tabular}

1

2 Carbonnier's group contributed a lot to the field of flow-through supported catalysis by

3 developing a series of chemically modified monolithic supports based on NAS. The generic

4 monolith was initially synthesized within microsized channels and further chemically

5 modified by taking advantage of the reactive of the $N$-hydroxysuccinimide moieties towards

6 nucleophilic species. Such in-capillary monoliths displayed a pore size of $2.25 \mu \mathrm{m}$ by MIP, a

7 surface area lower than $10 \mathrm{~m}^{2} \cdot \mathrm{g}^{-1}$ but a large porous volume of $c a .1 .5 \mathrm{~cm}^{3} \cdot \mathrm{g}^{-1}$ [25]. One of the

8 first examples described the preparation of diacid-decorated porous monolith [31]. Such

9 carboxylic acids were used to anchor copper nanoparticles using two immobilization

11 diameter in the range $40-60 \mathrm{~nm}$ ) were percolated into the monolithic structure and the

12 microreactor used directly after a rinsing step. On the other hand, $\mathrm{Cu}^{2+}$ ions were initially

13 immobilized onto the surface of the functionalized monolith. In a second step, an aqueous

$14 \mathrm{NaBH}_{4}$ solution was injected in the monolith to generating the nanoparticles through

15 reduction. Both microreactors were used to catalyze hydride-mediated reduction of one

16 nitroarene, the $o$-nitrophenol. The best yield $\left(68.5 \%\right.$ at a flow rate of $\left.0.3 \mu \mathrm{L} . \mathrm{min}^{-1}\right)$ was

17 obtained when preformed NPs were used while the in-situ approach led to slightly lower

18 yields (40 and $55 \%$ for flow rates of 4 and $1.5 \mu$ L. $\mathrm{min}^{-1}$, respectively) (Table 8).

19 In another implementation, the NAS-based monolith was used as support for gold 20 nanoparticles. As described in the work of Khalil et al. [147], ethylenediamine was grafted on 21 the monolith surface. The resulting primary amines, in their protonated form, were used as 22 ligands to immobilize Au colloids. Both ways of nanoparticles immobilization, namely in-situ 23 and ex-situ pathways were investigated. In the former case, an aqueous solution of $\mathrm{HAuCl}_{4}$ 
1 was percolated to immobilize $\mathrm{Au}^{3+}$ ions followed by reduction using an aqueous $\mathrm{NaBH}_{4}$

2 solution. For the ex-situ way, commercially available Au NPs with a diameter of $20 \mathrm{~nm}$ and a

3 citrate stabilization layer were used. Interaction between the carboxylates of the citrates and

4 the ammonium form of the primary amines at the pore surface provided strong interfacial

5 interaction, leading to robust anchoring of the nanoparticles. The microreactors were used for

6 nitroarenes reduction, using $p$-nitroaniline, $o$-nitrophenol, $m$-nitrophenol and $p$-nitrophenol as

7 model molecules. Different parameters were investigated to optimize the reaction yields, like

8 the reactants concentration, the column length, the flow rate allowing for complete conversion

9 of the nitroarenes into the corresponding aromatic amines. Of particular interest, it was shown

10 that the in-situ approach provided higher reaction yields as compared to the ex-situ using the

11 same flow conditions.

12 An extension of this work was provided in the paper by Liu et al. [146] were NAS-based 13 monoliths were functionalized with amine moieties derived from histamine. Commercially 14 available $\mathrm{Au}$ NPs with different sizes $5 \mathrm{~nm}, 20 \mathrm{~nm}$ (Fig. 7B) and $100 \mathrm{~nm}$ were used. The 15 aggregation behavior of the NPs at the monolith surface as well as the coverage density were 16 found to depend on the chemical nature of the amine ligand and size of the nanoparticles. 17 While the higher diameters (100 and $20 \mathrm{~nm}$ ) were the most homogeneously and densely 18 covered columns, difficulties were encountered with the $100 \mathrm{~nm} \mathrm{Au} \mathrm{NPs} \mathrm{in} \mathrm{the} \mathrm{filling} \mathrm{and} \mathrm{the}$ 19 back pressure obtained from the capillary. The catalytic efficiency of these microreactors was 20 first established for $p$-nitrophenol and then extended to dinitro derivatives, namely 2,521 dinitrophenol, 2,4-dinitroaniline, 2,6-dinitroaniline and 3,5-dinitroaniline. Interestingly, the 22 best results were obtained for the $20 \mathrm{~nm}$ nanoparticles, instead of the $5 \mathrm{~nm}$ ones, and for a 23 flowrate of $5 \mu \mathrm{L} \cdot \mathrm{min}^{-1}$ (Table 8). 
1 Table 8. Examples of nitro coupounds reactions achieved using polymer-supported metal 2 nanoparticles. The reactions conditions and yields are also presented.

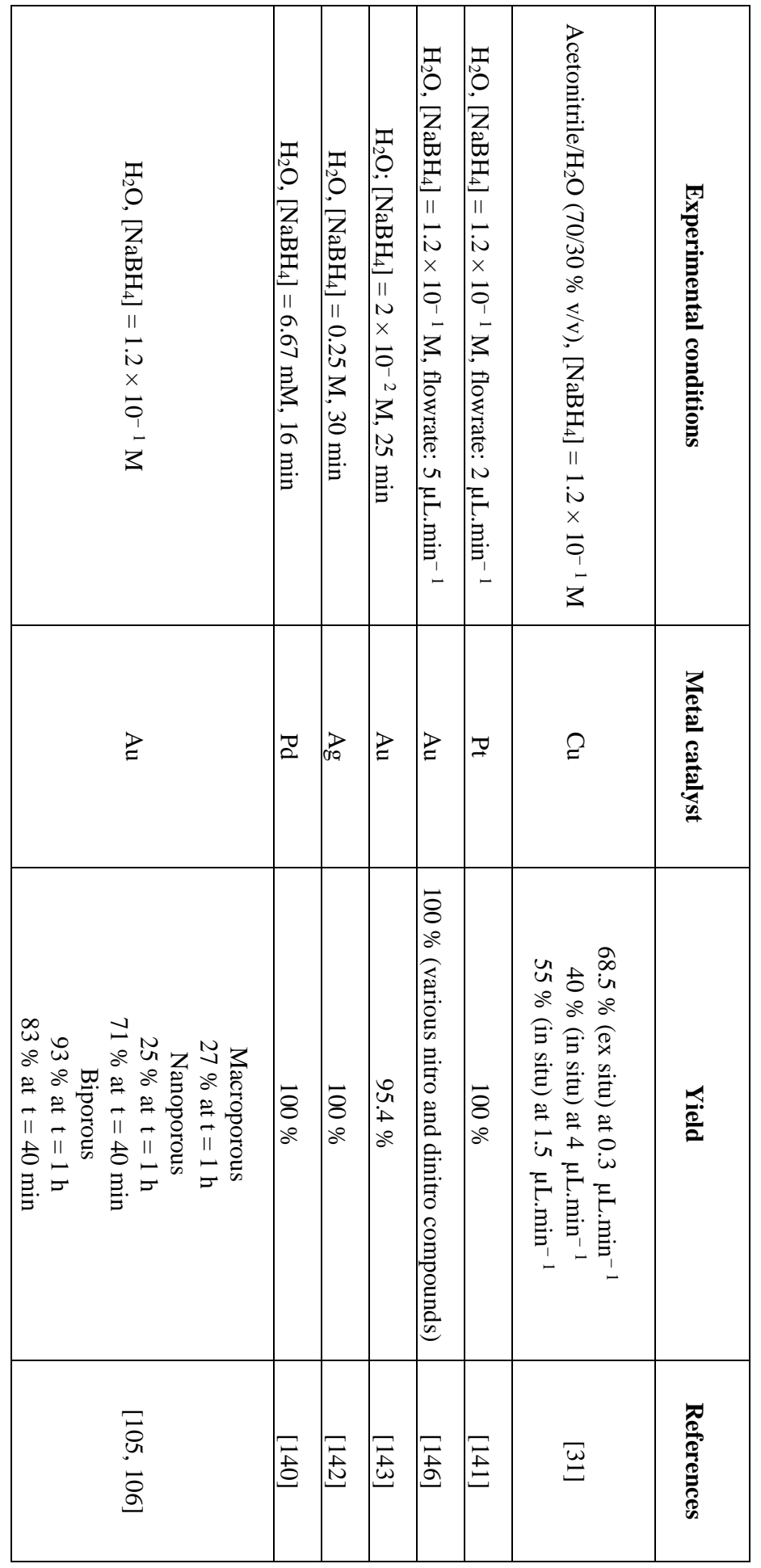

4 Moreover, Carbonnier's group developed a new monolithic matrix, based on glycerol

5 carbonate methacrylate [141]. Such a carbonate ring can be easily converted into a urethane

6 group when reacting with a suitably chosen amine-bearing molecule. A determination of the 
1 pore size of these in-capillary monoliths was achieved using mercury intrusion porosimetry.

2 The authors found an average pore size centered around $2.2 \mu \mathrm{m}$ but also another lower

3 porosity level in the $50 \mathrm{~nm}$ range that was not visible by SEM because of the detection limit

4 of the apparatus. Carboxylic acids were grafted at the surface via a two-step process and then

5 used to chelate platinum ions. $\mathrm{NaBH}_{4}$ was used as a reducing agent for the generation of $\mathrm{Pt}$

6 NPs directly onto the pore surface. The as-prepared supported catalyst was further used for

7 the total reduction of $p$-nitrophenol (Table 8).

8 Beside the design of porous materials for flow-through applications, Poupart et al. also

9 prepared bulk polymeric materials using the porogenic solvent approach. A dimethacrylate monomer bearing a disulfide bridge, namely bis(2-methacryloyl)oxyethyl disulfide 11 (DSDMA), was used with the aim to eventually produce thiol-containing monoliths [159].

12 Such an approach was followed because of the difficulty to polymerize thiol-containing monomers with the occurrence of chain transfer reactions. Herein, they used a protected thiol in the form of disulfide. After polymerization with a dimethacrylate as a cross-linker and using toluene as a porogenic agent, thiols were generated using D,L-dithiothreitol (DTT).

16 Several solvents were used as porogens (methanol, ethanol, a cyclohexanol/dodecanol 17 mixture as well as toluene). Mercury intrusion porosimetry was performed on all samples, even after DTT-mediated cleavage of the disulfide bridge contained in the monoliths. Average pore sizes of 6 and $0.5 \mu \mathrm{m}$ were determined for methanol and ethanol, respectively. Similarly, average pore sizes of 0.01 and $1 \mu \mathrm{m}$ were obtained for the cyclohexanol/dodecanol mixture and toluene, respectively. No significant variation of pore size or porosity ratio was found upon selective cleavage of disulfide bridges. Gold ions were subsequently anchored to the thiolated surface and further reduced using sodium borohydride to generate $\mathrm{Au}$ nanoparticles (Fig. 7C). Although aggregation trends could be seen onto the SEM pictures, the as-prepared bulk catalysts were used to reduce an organic dye, Eosin Y. Up to six consecutives catalytic 
1 cycles were tested with an average yield of about $60 \%$, thus ascertaining the reusability of the 2 supported catalyst.

\section{$4 \quad 3.3 \quad$ Nanoparticles supported by nanoporous polymers}

5 As previously discussed, pore sizes of nanoporous materials are appealing for catalysis

6 applications, as they can provide a filtration phenomenon occurring simultaneously to the catalytic activity. Few examples in the literature described the use of nanoporous polymers arising from diblock copolymers. The first example of nanopore decoration with a metal was reported by Ryu et al. [67] who generated gold nanorods at the interface of thiolated polymers. Unfortunately, the authors did not mention any application. Recently, Grande's

11 group started to investigate how such pores could be decorated with nanoparticles and considered the use of the resulting composite materials as supported catalysts. In 2015, the synthesis of a diblock copolymer made of PS and PLA and bearing a disulfide bridge junction between both blocks was first developed [66]. After the synthesis of the dual initiator and both blocks by ATRP and ROP, an orientation step of the resulting functional copolymer was implemented using a channel die process. Cleavage of the disulfide bridge 17 was achieved using triphenylphosphine (TPP), revealing the pores as well as the thiol moieties at the pore interface. $\mathrm{Au}^{3+}$ ions were then immobilized and further reduced with $\mathrm{NaBH}_{4}$. The as-obtained porous polymer-supported gold nanoparticles were used as efficient catalysts to reduce $p$-nitrophenol. Reaction yields of $\approx 70 \%$ were calculated after $1 \mathrm{~h}$ of 21 reaction for five consecutive catalytic runs.

22 In another implementation, the same authors used an acetal junction between the two blocks 23 [63]. The dual initiator was synthetized via a two-step process, and after the polymerization 24 processes, orientation of the block copolymer structure was performed via solvent vapour 25 annealing of films casted onto Si wafers. The acetal link between both blocks could be easily 
1 cleaved with trifluoroacetic acid and then, functionalized with amine molecules after

2 reductive amination reaction. Amine-decorated pores were covered with in-situ generated 3 gold nanoparticles (Fig. 8A). First, boronic homocoupling and nitroarene reduction were

4 considered separately. Finally, the two reactions were coupled in a cascade reaction process

5 involving 3-nitrobenzene boronic acid. After formation of the 3,3'-dinitrobiphenyl through

6 homocoupling reaction, the nitro moieties were successfully reduced using $\mathrm{NaBH}_{4}$-mediated

7 reduction yielding 3,3'-diaminobiphenyl as a major product. 

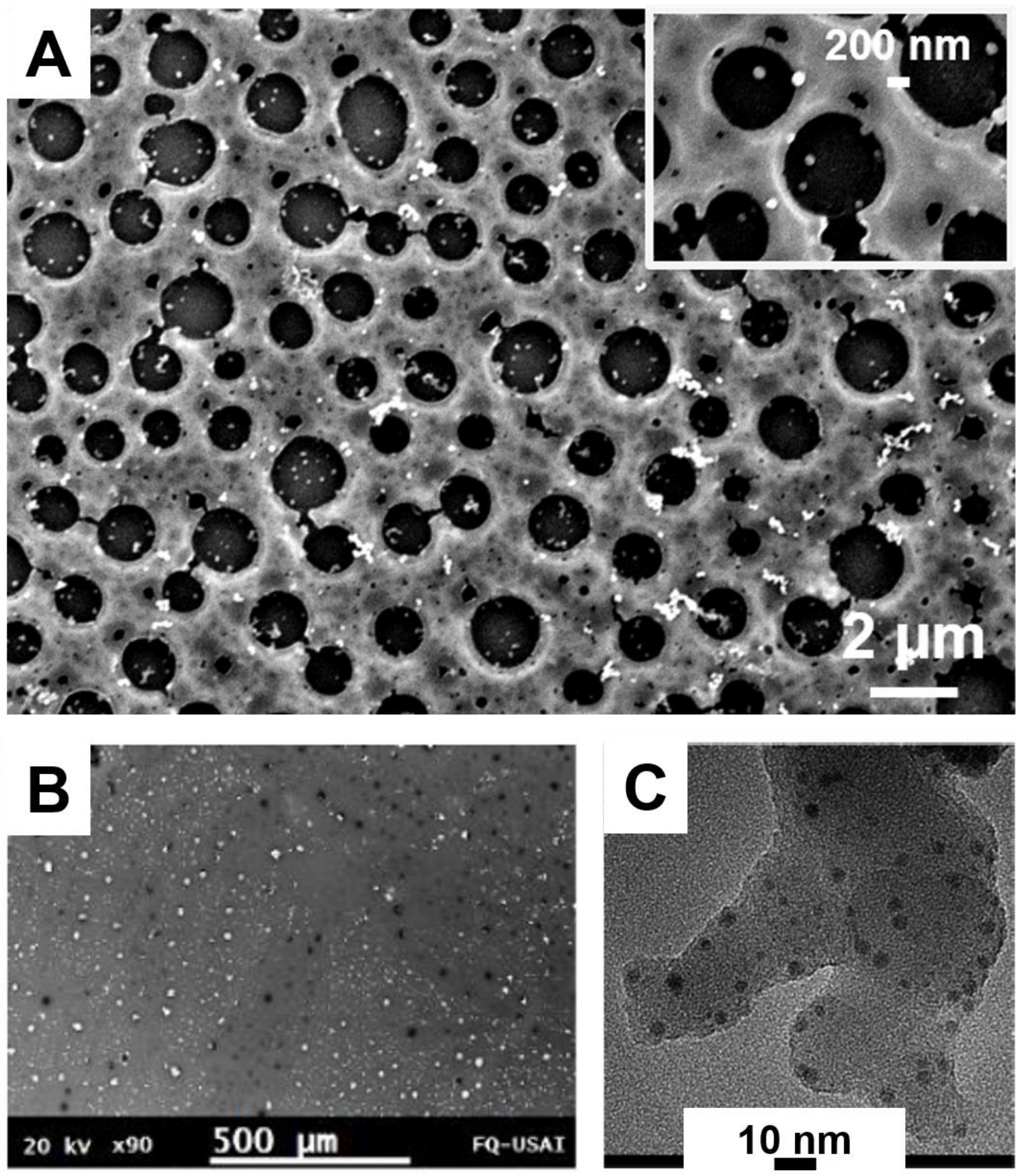

2 Fig. 8. Examples of nanoporous polymeric materials bearing metallic nanoparticles. A) in-situ

3 generated $\mathrm{Au}$ NPs onto a PS arising from diblock copolymers. [63], Copyright 2017

4 (Reproduced with permission from the American Chemical Society). B) in-situ generated Au

5 NPs within a cellulose membrane. [143], Copyright 2017 (Reproduced with permission from

6 Wiley VCH). C) in-situ generated Pd NPs onto a microporous polyheptazine. [155],

7 Copyright 2017 (Reproduced with permission from the American Chemical Society). 
1 Besides the use of diblock copolymers, several authors have implemented polymer-based

2 membrane materials exhibiting nanoporosity to design supported catalysts. Remigy and

3 Lahitte's group discussed the use of commercially available polyethersulfone membranes

4 with a pore size of $200 \mathrm{~nm}$. The membranes were modified to anchor Pd NPs and further used

5 in several reactions, including nitrophenol reduction [144, 145], Suzuki-Miyaura cross

6 coupling [145, 152, 153] (Table 7) or hydrogenation of trans-4-phenyl-3-buten-2-one [163].

7 Interesting comparison was performed considering the use of these membranes in batch mode

8 and under flow-through conditions. The latter conditions proved to be superior providing

9 faster reactions. Indeed, while the reactions could be performed within a $10 \mathrm{~s}$ range in flow

10 conditions, the batch mode required $6 \mathrm{~h}$ for full conversion. Another interesting result was

11 that no byproducts were observed in the flow-through mode. This was assumedly assigned to

12 a lower kinetic of formation of the side product.

13 Other research groups focused on using membranes with embedded nanoparticles. One may

14 cite the work from Mora-Tamez et al. [143] who considered the use of Au NPs immobilized

15 within cellulose triacetate-based membranes. The originality of the approach lies in the

16 extraction of $\mathrm{Au}^{(\mathrm{III})}$ ions by the membranes and their simultaneous in-situ reduction with a

17 citrate solution (Fig. 8B). Such supports with embedded NPs were used for the reduction of $p$ -

18 nitrophenol. The authors mentioned reaction yield as high as $95.4 \%$ after 25 min of reaction

19 (Table 8). Membranes were also characterized using BET and nitrogen adsorption/desorption

20 isotherms. Specific surface area values ranging from 67 to $137 \mathrm{~m}^{2} \cdot \mathrm{g}^{-1}$ and pore volume values

21 from 0.048 to $0.097 \mathrm{~mL} \cdot \mathrm{g}^{-1}$ were found.

22 Likewise, Clark's group used biobased nanoporous polymers for catalysis purposes. Starch23 based porous supports were obtained by solvent exchange between water and ethanol, and 24 subsequently used to anchor palladium nanoparticles [151]. Palladium acetate was put in the 25 presence of the starch-based materials acting simultaneously as reducing agent and support 
1 for the resulting nanoparticles, seemingly self-reducing the precursory metallic ions. Such

2 polymeric materials, characterized by $\mathrm{N}_{2}$ physisorption, exhibited a specific surface area of $3190 \mathrm{~m}^{2} \cdot \mathrm{g}^{-1}$ and an average pore size of $8.2 \mathrm{~nm}$ through the BET equations (Equation 2 and

4 Equation 3) as well as the BJH method, respectively. Mizoroki-Heck (Table 7), Sonogashira

5 (Table 7) and Suzuki-Miyaura reactions were performed under microwave irradiation using

6 the starch-supported Pd NPs. The microwave activation permitted to reduce the reaction time

7 as the reactions could be achieved in less than $10 \mathrm{~min}$. In contrast, the authors provided a comparison with other data published in the literature without the use of microwave and for which the reaction times were in the range of $4-12 \mathrm{~h}$. Although the authors concluded on the superiority of the starch-based materials in terms of improved reaction yields, lower reaction

11 times, and renewability of the catalysts, a reliable comparison with traditional catalysts such as $\mathrm{Pd} / \mathrm{C}$ or silica-supported NPs is, to our point of view, very difficult because most of the studies that the authors referred to did not mention the use of microwave activation.

Finally, microporous polymers (with pores below $2 \mathrm{~nm}$ ) were used as catalytic supports. Although most of examples in the literature mentioned the direct use of a polymer network as the heterogeneous catalyst due to a specific site like a specific chemical moiety [168] or a metallo-organic complex [169], some examples about polymer-supported nanoparticles can also be found. Zhang et al. [154] designed a porous network via a direct Sonogashira coupling of an aromatic trialkyne and 1,4-dibromobenzene. The as-obtained nanoporous polymer was further characterized using $\mathrm{N}_{2}$ sorption. First, BET measurements gave a specific surface area of $421 \mathrm{~m}^{2} \cdot \mathrm{g}^{-1}$ and a pore volume of $0.27 \mathrm{~mL} \cdot \mathrm{g}^{-1}$. In this case, the pore size was not determined using the BJH theory but was calculated by the nonlocal density functional theory (NLDFT), a computational quantum mechanical modelling that allowed for highlighting the presence of three populations of pores in such a material with sizes centered on $0.6,1.3$, and $3.1 \mathrm{~nm}$. The polymeric material was subsequently immersed into an acetone solution of $\mathrm{Pd}(\mathrm{OAc})_{2}$. After 
1 stirring at $90{ }^{\circ} \mathrm{C}$, a Pd NPs-loaded polymer was obtained. Different Suzuki-Miyaura C-C

2 coupling reactions were performed using a large panel of halogenoarenes (iodo and bromo)

3 along with phenylboronic acid. High yields (> $85 \%)$ and short reaction times (less than 4 h)

4 were obtained. Comparison with $\mathrm{Pd} / \mathrm{C}$ catalysts suggested that such nano Pd-decorated

5 frameworks allowed for a threefold decrease of the reaction times (from $9 \mathrm{~h}$ for $\mathrm{Pd} / \mathrm{C}$ to $3 \mathrm{~h}$ )

6 to reach similar reaction yields. Five catalytic cycles were performed and only a limited

7 reduction in catalytic activity was observed as expressed by the decrease of a few percent of

8 the reaction yields, while leaching effect was quantified to be less than $1 \%$ for each cycle.

9 In their interesting work, Du et al. [155] prepared polymer networks through a nucleophilic 10 substitution of chlorines pending on the cyameluric chloride monomer by amines of 11 piperazine. The as-obtained heptazine framework was immersed into an acetone solution of 12 palladium acetate under reflux, allowing for the generation of the Pd NPs by self-reduction 13 (Fig. 8c). Similarly to the studies achieved by Zhang et al. about microporous polymeric 14 materials, the surface area of their porous heptazine framework was also determined through 15 BET measurements using nitrogen sorption. Surface area of 106 and $73 \mathrm{~cm}^{2} \cdot \mathrm{g}^{-1}$ and pore 16 volume of 0.43 and $0.33 \mathrm{~mL} \cdot \mathrm{g}^{-1}$ were found by the authors for the materials before and after 17 immobilization of Pd NPs, respectively. Such surface area values are rather unexpected; one would indeed expect higher values for hybrid materials, likely due to the adsorption of metallic nanoparticles at the pore surface of these polymeric frameworks. Pore size distribution was also found in the 2-8 $\mathrm{nm}$ range. With such hybrid catalysts, Suzuki-Miyaura 21 couplings were performed using different pairs of bromoarenes derivatives and phenylboronic 22 acids. Yields above $80 \%$ of conversion were obtained except for the 2-bromonaphtalene 23 along with the arylboronic acid as well as for the 4-nitrobenzene boronic acid along with 24 bromobenzene, for which yields remained below $40 \%$. A tentative explanation for the 25 obtained yields was provided by the authors based on the large steric hindrance of 2- 
1 bromonaphtalene as well as the poor solubility of 4-nitrobenzene boronic acid. Here again,

2 five catalytic runs were performed consecutively showing a limited decrease of the catalytic

3 activity and ICP measurements performed before and after the five cycles showed negligible

4 leaching phenomena.

$6 \quad 3.4 \quad$ Nanoparticles supported by biporous polymers

Macroporous and nanoporous polymers are very different systems in terms or permeability, porosity, surface area which are key features for catalysis applications. Macroporous polymers possess large pores providing enhanced permeability for the liquid to penetrate into the pores but a poor specific surface area. In contrast, nanoporous frameworks

11 afford a larger specific surface area, while a lower accessibility to the pores. A high 12 permeability may favor better accessibility of the reactants to the catalysts, while a large specific surface area should allow for higher density of metal nanoparticles on the support surface. If considered simultaneously, these two criteria may provide more efficient catalytic processes. Based on this simple consideration, biporous materials containing both macropores and nanopores may appear as attractive candidates for nanocatalyst supports.

17 An easy way of making biporous materials relies on the fabrication of polyHIPEs. One of the pioneering groups in the field of polyHIPE preparation and use as catalysts is Deleuze's. In 2005, they described polystyrene- [162] and poly(vinylbenzyl chloride)-based [156] polyHIPEs as supports for in-situ generated Pd NPs (Fig. 9A). Both styrene and VBC-based 21 polymeric supports showed a specific surface area of $902 \mathrm{~m}^{2} \cdot \mathrm{g}^{-1}$ as determined by BET, while 22 pore size distribution in the $10-80 \mathrm{~nm}$ range was induced by a porogenic solvent added to the 23 HIPE polymerization feed. The hybrid supports were used for the hydrogenation of an alkene, 24 i.e. allyl alcohol, and for Suzuki-Miyaura cross-coupling reactions (Table 7). The authors reported reaction times of $1 \mathrm{~h}$ and $70 \mathrm{~h}$ for near-completion hydrogenation and coupling 
1 reactions, respectively. The authors discussed their results with respect to other published

2 results obtained with catalysts such as $\mathrm{Pd} / \mathrm{C}$ using the prepared supported catalysts in powder

3 forms. Polystyrene based polyHIPEs were also used by the same group as supports for gold

4 nanoparticles [100]. In this case, $\mathrm{HAuCl}_{4}$ ions solutions were simply deposited and the PS

5 induced self-reduction. Supported Au NPs were then used for the reduction of a dye, Eosin Y,

6 and the reaction was repeated three times. Near-completion reactions were achieved within

7 one hour and under mild conditions $\left(25^{\circ} \mathrm{C}\right)$. Pores in the $200-291 \mu \mathrm{m}$ range, were found for

8 such monoliths depending on the samples, while a porosity ratio of $82 \%$ was found by MIP.

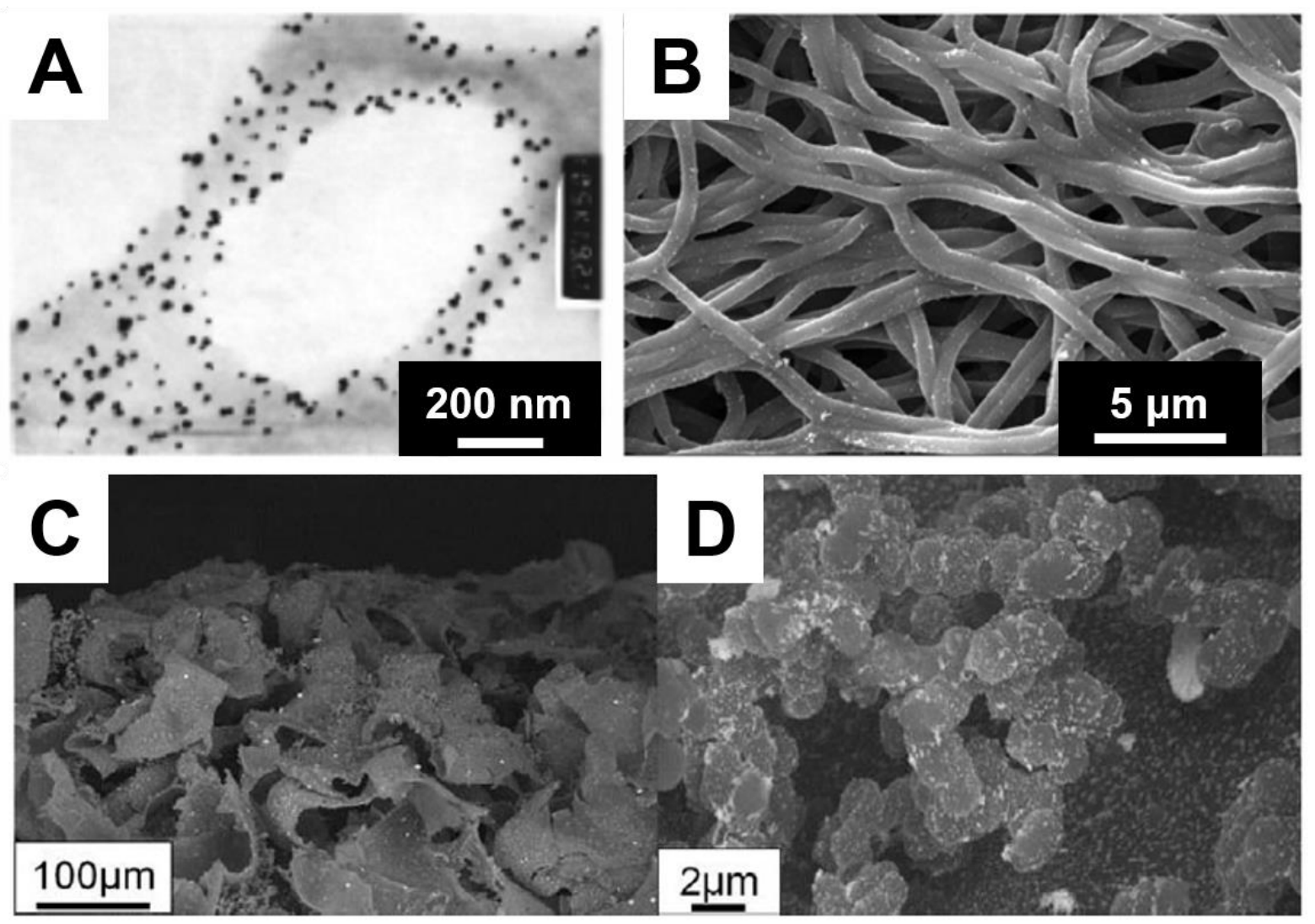

10 Fig. 9. Examples of biporous polymeric materials bearing metallic nanoparticles. (A) in-situ 11 generated Pd NPs onto a PS polyHIPE. [162], Copyright 2005 (Reproduced with permission 12 from the American Chemical Society). (B) in-situ generated Ag NPs onto poly(acrylic acid) 13 fibers. [142], Copyright 2012 (Reproduced with permission from the Royal Society of 14 Chemistry). (C), (D) in-situ generated Au NPs onto a biporous poly(HEMA-co-EGDMA) 15 bulk monolith. [104], Copyright 2016 (Reproduced with permission from Wiley VCH). 
1 Another way to design nanostructured catalysts relies on the use of electrospun materials. The

2 as-obtained fibers possess several interesting properties for catalytic applications, such as a

3 large surface to volume ratio and superior mechanical properties. Therefore, they are also

4 usually used as membrane-like materials, which can be beneficial to catalysis, as discussed

5 above. To date, electrospun materials have been mostly used for environmental catalytic

6 applications, like hexavalent chromium $\left(\mathrm{Cr}^{\mathrm{VI}}\right)$ or nitro group reduction. Nevertheless, as-

7 prepared electrospun supports are not widely used as catalyst supports, as most reports in the

8 literature mentioned the use of the polymer mats as precursors for calcination for, as an

9 example, creating titania fibers. Most examples in the literature describe the use of polymer

10 fibers already containing chelating moieties like carboxylic acids or amines. Shi's group

11 described the use of polyethyleneimine (PEI) blended with poly(vinyl alcohol) (PVA) as mats

12 for the support of gold [148] and palladium [164] nanoparticles. Au NPs were used for the

13 successful reduction of nitro compounds, while Pd NPs were applied to the generation of $\mathrm{Cr}^{\mathrm{III}}$

14 from $\mathrm{Cr}^{\mathrm{VI}}$, which is highly carcinogenic. In the same way, Xiao's group used a blend of

15 poly(acrylic acid) (PAA) and PVA to chelate in-situ generated (sodium borohydride as

16 reducing agent) Ag NPs (Fig. 9B) for the catalytic reduction of $p$-nitrophenol [142] (Table 8).

17 Another interesting recent work is that from Pandey's team [140], who used electrospinning

18 to prepare poly(ether sulfone) (PES) fibers and took advantage of the presence of the ether

19 sulfone moieties to perform photolysis under UV irradiation to initiate the growth of

20 polyGMA chains. The pendant oxirane groups were then opened with hydrazine providing

21 directly attachment of the reducing agents on the support surface. A palladium salt was put in

22 contact with the fibers via an aqueous solution of palladium chloride and self-reduced. Hybrid

23 fibers were applied to the reduction of hexavalent chromium as well as $p$-nitrophenol (Table

24 8) but also the less common reduction of hexavalent uranium $\left(\mathrm{U}^{\mathrm{VI}}\right)$ to $\mathrm{U}^{\mathrm{IV}}$. 
1 Last but not least, one may mention the use of the double porogen templating approach

2 allowing for easily combining two levels of porosity and broadening the range of accessible

3 pore shape. Ly et al. recently designed doubly porous PHEMA-based materials as supports

4 for gold nanoparticles [105, 106] (Fig. 9C). They used fused $\mathrm{NaCl}$ particles as macroporogens

5 and isopropanol as a porogenic solvent for the production of the nanopores. The obtained

6 monoliths, i.e. monoporous with the higher porosity level, monoporous with the lower

7 porosity level and biporous ones, have been thoroughly characterized through mercury

8 intrusion porosimetry by using the Washburn equation (Equation 1). Data gathered in this

9 study showed that average pore sizes of $42 \mu \mathrm{m}, 9 \mu \mathrm{m}, 40 \mu \mathrm{m}$, and $8 \mu \mathrm{m}$ were obtained by

10 MIP for monoporous with the higher porosity level, monoporous with the lower porosity level

11 and biporous HEMA-based polymeric frameworks, respectively. More importantly, the

12 porosity ratio of such a biporous polymer was estimated to be $92 \%$, which could be of

13 upmost interest for heterogeneous supported catalysis applications. The surface of the

14 biporous polymers was chemically modified in order to have amines or thiols directly on the

15 surface. $\mathrm{HAuCl}_{4}$ solution was used to load gold ions onto the surface and $\mathrm{NaBH}_{4}$ was used as

16 a reducing agent. Reduction of 4-nitrophenol was performed in order to prove the catalytic

17 efficiency of the as-prepared hybrids. Differences in the size and/or distribution of the

18 nanoparticles were observed as a function of the nature of the chelating group $\left(-\mathrm{NH}_{2} v s .-\mathrm{SH}\right)$,

19 thus leading to differences in the reaction yields. It was shown that thiol functions led to

20 bigger nanoparticles, and also surprisingly to leaching of NPs. Monoporous materials were

21 also synthetized in order to highlight the superiority of such doubly porous materials. While

22 monomodal porous polymers, i.e. with macroporosity or nanoporosity only, showed rather

23 similar efficiency, the doubly porous homologues exhibited higher catalytic activity. The

24 higher density of nanoparticles associated with the latters along with their higher porosity 
1 ratios as compared to the nanoporous and macroporous materials were assumed to account for 2 such results (Table 8).

\section{Critical appraisal of the different strategies}

This review presented a critically selected overview of the various polymeric materials so far implemented as potential supports for the adsorption of metallic nanoparticles meant for supported heterogeneous catalysis. Each of these systems has inherent advantages/drawbacks depending on their preparation conditions, etc. This section will bring a critical appraisal of the different porous polymeric systems in terms of preparation, main characteristics, catalytic properties, durability, etc. and of the related hybrid systems and their catalytic properties.

Fused silica capillaries filled with polymer monoliths are easy to prepare, dynamic loading of the reactants in such microsystems being an undeniable advantage for the successful functionalization of the pore surface with chemical grafts of interest and successive immobilization of metallic nanoparticles through the in situ or ex situ strategies. In this way, each preparation step is completed in a few hours or even in a few minutes. Supported catalytic reactions operated in flow-through conditions have the major advantage to directly give the desired product, without the need for any further purification step, provided of course that no byproduct(s) is (are) generated during the catalytic reaction. More interestingly, such microsystems are supposed to be easily scaled up and might be used in automation processes, as mentioned by Nikbin et al. [149], that is to say that a chromatographic-column sized 21 catalytic reactor would be able to do what a tiny in-capillary microreactor can do. Such a 22 scale-up process would definitely solve the major issue regarding in-capillary monolithic 23 hybrid reactors, such as slow flow rates (about a few $\mu$ L.min ${ }^{-1}$ ) due to rather high 24 backpressures and limited quantities of reactants that can be converted, i.e. generally a few 25 milligrams, due to microcolumns size/volume. Too high backpressures dramatically decrease 
1 the lifetime of the column, reducing its reusability/durability. Moreover, such important

2 backpressure phenomena might lead to a higher leaching of adsorbed metallic nanoparticles,

3 which would be detrimental to further flow-through supported catalytic processes.

4 Nanoporous polymers arising from diblock copolymers can lead to different controlled 5 accessible morphologies (from cylinders to gyroids or to lamellae), thus enabling to tune the

6 porosity of the support. Nevertheless, a non-negligible series of not trivial synthetic steps is

7 required to produce them, which could be detrimental for their transfer to industrial processes.

8 Besides, depending on the alignment procedure and on the quantities of copolymer needed,

9 the orientation procedure time can be dramatically increased. For channel die processing, a

10 few hundreds of milligrams of copolymers are required to determine the best orientation

11 conditions, while for solvent vapour annealing, a diluted copolymer solution is enough for

12 film nanostructuration on silicon wafers. Yet, there is no widespread use of these nanoporous 13 materials for catalysis purposes.

14 Polymeric membranes seem to be the candidates of choice for efficient supported catalytic 15 reactions. However, some drawbacks could be found [170]. First, they need a specifically 16 designed and optimized reactor. Unfortunately, the production costs for a specific reactor 17 chamber must be added to the efforts for creating catalytic membranes, which are not trivial. 18 Moreover, as with capillary-based microreactors, a specific adjustment of the flow rate of reactant solution to reach optimized reaction rates is necessary. Finally, one should keep in 20 mind that polymeric membranes are known to have a limited durability, depending especially 21 on their thermal, chemical, and mechanical properties. Indeed, the harsher the catalytic 22 reaction conditions, the quicker they degrade, adding higher costs of renewal, even if some 23 improvements have been achieved regarding the durability of such polymer-based 24 membranes. 
1 Microporous networks have one major advantage, namely their specific surface area. Indeed,

2 the pores consist in voids generated by the monomer assembly, and are in the micropore

3 range. This could logically lead to catalytic supports declined for reactions in the gas phase.

4 Yet, examples of catalytic reactions in liquid media still exist with such polymer-based

5 microporous supports. However, they have a low permeability, and this is especially true for

6 pure carbon-based networks [171]. This limitation could notably prevent catalytic reactions

7 from occurring efficiently.

8 PolyHIPEs display a really well-accessible high porosity with interconnected pores that

9 enable high flow-through processes. However, since the void size is large (cavities are in the

10 tens/hundreds of micrometers range), specific surface areas are quite low [172]. Works

11 achieved by Sherrington's group attempted to overcome this issue [173], notably by using

12 porogenic solvents in addition to the HIPE process. However, resulting porous polymers

13 faced a new limitation, i.e. poor mechanical resistance of the monolith during flow-through

14 processes or even collapse of the porous structure.

15 Electrospun materials have risen since the mid 1990's, period during which such polymeric

16 fibers could be implemented for nanotechnology applications. As catalytic support, they offer

17 an interconnected porosity resulting from their engineering process. Moreover, they are

18 already used to prepared filtration membranes, which may lead to flow-through catalytic

19 reactors. Nevertheless, some limitations still exist. One may mention the difficulty to produce

20 uniform mats with a fiber diameter lower than $50 \mathrm{~nm}$ [174]. Indeed, a smaller diameter of

21 polymeric fiber would lead to a smaller volume of these fibers, thus enhancing the surface to

22 volume ratio. Progress is already on the way to overcome this issue by studying the solvent

23 evaporation during the electrospinning process, among others.

24 Finally, the double porogen approach affords high porosity ratios (> 90\%) and interconnected

25 porosities, provided that the porogens are suitably chosen. However, further investigation still 
1 needs to be performed to clearly correlate the pore morphology to the mass transfer properties

2 of the resulting materials. Very few of such doubly porous crosslinked polymers have been

3 used so far in the area of heterogeneous supported catalysis, only bringing limited information

4 in the field. Finally, no mechanical characterization data have been published yet on such

5 catalytic supports, which could bring some interesting information on their resistance to

6 different experimental conditions.

7

\section{Conclusions and prospects}

In conclusion, this review critically overviews the main types of polymers used as potentially interesting supports for metallic nanoparticle immobilization. The as-prepared

11 hybrid materials seem to constitute candidates of choice in the area of heterogeneous 12 supported catalysis, as demonstrated by some notable works performed gathered in this review article. Production costs for these porous polymers remain rather low, when compared to their inorganic counterparts, while their preparation is rapid, making them suitable for various applications, including heterogeneous supported catalysis. However, progress for 16 optimizing such polymer-based supports remains a milestone in order to optimize the 17 resulting hybrid materials. For instance, the optimization of specific surface area of such porous polymers is of upmost importance, as it would definitely bring such organic materials a step forward when compared to their inorganic counterparts. It was recently demonstrated that HEMA-based porous polymers arising from reversed HIPEs can be further 21 hypercrosslinked through a two-step synthetic pathway to generate porous polymers with 22 largely enhanced surface area of about $1500 \mathrm{~m}^{2} \cdot \mathrm{g}^{-1}$ [175]. Another very promising research area could rely on the development of porous metallic nanoparticles. Indeed, such nanometals

24 can develop a very large specific surface area, e.g. $8973 \mathrm{~m}^{2} \cdot \mathrm{g}^{-1}$ for the outer surface area and $2558724 \mathrm{~m}^{2} \cdot \mathrm{g}^{-1}$ for the inner surface area of $80 \mathrm{~nm}$ hollow porous gold nanoparticles, and thus 
1 constitute promising candidates for the development of adsorbed catalysts at the surface of

2 porous polymers. The Holy Grail of such research area would rely on the preparation of

3 advanced hybrid systems that would be constituted of both high surface area counterparts, i.e.

4 porous nanometal and porous polymer support. Other morphologies of metallic nanoparticles

5 could also be largely envisioned as they could also lead to enhanced activities of the resulting

6 supported nanocatalysts [176].

7 Based on this overview concerning porous polymers meant for heterogeneous supported 8 catalysis, different key experimental parameters have to be indeed carefully taken into 9 consideration and especially porosity range and morphology of the materials as well as nature 10 of chemical moieties exposed at the pore surface so as to optimize the interactions between 11 the support and the metal (precursor). The catalytic processes involved, namely batch or flow12 through, but also the envisioned catalytic reaction are crucial parameters that matter for the 13 appropriate selection of the supports, notably regarding the stability and durability of the 14 hybrid systems in diverse experimental conditions (temperature, pressure, solvent nature, 15 etc.). Beyond the application of such hybrid systems in supported heterogeneous catalysis, it 16 is essential noticing that they could also be used as sensors or sorbents in analytical sciences, 17 filters for $\mathrm{CO}_{2}$ sorption, or nanoreactors for the capture and release of biomolecules such as cysteine-bearing peptides/proteins, for instance.

\section{Acknowledgments}

22 Financial support from CNRS and UPEC is gratefully acknowledged. The authors are indebted to UPEC for providing R. Poupart with a Ph.D. grant. 
[1] Van Leeuwen PW. Homogeneous catalysis: understanding the art: Springer Science \& Business Media; 2006.

[2] Widegren JA, Finke RG. A review of the problem of distinguishing true homogeneous catalysis from soluble or other metal-particle heterogeneous catalysis under reducing conditions. J Mol Catal A: Chem 2003; 198: 317-41.

[3] Herrmann WA, Kohlpaintner CW, Manetsberger RB, Bahrmann H, Kottmann H. Watersoluble metal complexes and catalysts. J Mol Catal A: Chem 1995; 97: 65-72.

[4] Pirkanniemi K, Sillanpää M. Heterogeneous water phase catalysis as an environmental application: a review. Chemosphere 2002; 48: 1047-60.

[5] Bell AT. The Impact of Nanoscience on Heterogeneous Catalysis. Science 2003; 299: 1688.

[6] Copéret C, Chabanas M, Petroff Saint-Arroman R, Basset J-M. Homogeneous and Heterogeneous Catalysis: Bridging the Gap through Surface Organometallic Chemistry. Angew Chem Int Ed 2003; 42: 156-81.

[7] Lu A-H, Salabas EL, Schüth F. Magnetic Nanoparticles: Synthesis, Protection, Functionalization, and Application. Angew Chem Int Ed 2007; 46: 1222-44.

[8] Sachtler WMH, Zhang Z. Zeolite-Supported Transition Metal Catalysts*. In: D.D. Eley HP, Paul BW, editors. Advances in Catalysis: Academic Press; 1993. p. 129-220.

[9] Opanasenko M, Stepnicka P, Cejka J. Heterogeneous Pd catalysts supported on silica matrices. RSC Adv 2014; 4: 65137-62.

[10] Zhao D, Huo Q, Feng J, Chmelka BF, Stucky GD. Nonionic Triblock and Star Diblock Copolymer and Oligomeric Surfactant Syntheses of Highly Ordered, Hydrothermally Stable, Mesoporous Silica Structures. J Am Chem Soc 1998; 120: 6024-36.

[11] Wildgoose GG, Banks CE, Compton RG. Metal Nanoparticles and Related Materials Supported on Carbon Nanotubes: Methods and Applications. Small 2006; 2: 182-93.

[12] Liu J, Chen L, Cui H, Zhang J, Zhang L, Su C-Y. Applications of metal-organic frameworks in heterogeneous supramolecular catalysis. Chem Soc Rev 2014; 43: 6011-61.

[13] Vikrant K, Kumar V, Kim K-H, Kukkar D. Metal-organic frameworks (MOFs): potential and challenges for capture and abatement of ammonia. J Mater Chem A 2017; 5: 22877-96.

[14] Wu D, Xu F, Sun B, Fu R, He H, Matyjaszewski K. Design and Preparation of Porous Polymers. Chem Rev 2012; 112: 3959-4015.

[15] Seidl J, Malinský J, Dušek K, Heitz W. Makroporöse Styrol-Divinylbenzol-Copolymere und ihre Verwendung in der Chromatographie und zur Darstellung von Ionenaustauschern. Fortschritte der Hochpolymeren-Forschung. Berlin, Heidelberg: Springer Berlin Heidelberg; 1967. p. 113-213.

[16] Svec F, Fréchet JMJ. New Designs of Macroporous Polymers and Supports: From Separation to Biocatalysis. Science 1996; 273: 205-11.

[17] Svec F, Fréchet JMJ. Modified poly(glycidyl methacrylate-co-ethylene dimethacrylate) continuous rod columns for preparative-scale ion-exchange chromatography of proteins. $\mathrm{J}$ Chromatogr A 1995; 702: 89-95.

[18] Xu Y, Cao Q, Svec F, Fréchet JMJ. Porous Polymer Monolithic Column with SurfaceBound Gold Nanoparticles for the Capture and Separation of Cysteine-Containing Peptides. Anal Chem 2010; 82: 3352-8.

[19] Luo Q, Zou H, Xiao X, Guo Z, Kong L, Mao X. Chromatographic separation of proteins on metal immobilized iminodiacetic acid-bound molded monolithic rods of macroporous poly(glycidyl methacrylate-co-ethylene dimethacrylate). J Chromatogr A 2001; 926: 255-64. 
[20] Floris P, Twamley B, Nesterenko PN, Paull B, Connolly D. Agglomerated polymer monoliths with bimetallic nano-particles as flow-through micro-reactors. Microchim Acta 2012; 179: 149-56.

[21] Gusev I, Huang X, Horváth C. Capillary columns with in situ formed porous monolithic packing for micro high-performance liquid chromatography and capillary electrochromatography. J Chromatogr A 1999; 855: 273-90.

[22] Lv Y, Lin Z, Svec F. Hypercrosslinked Large Surface Area Porous Polymer Monoliths for Hydrophilic Interaction Liquid Chromatography of Small Molecules Featuring Zwitterionic Functionalities Attached to Gold Nanoparticles Held in Layered Structure. Anal Chem 2012; 84: 8457-60.

[23] Xie S, Svec F, Fréchet JMJ. Design of reactive porous polymer supports for high throughput bioreactors: Poly(2-vinyl-4,4-dimethylazlactone-co-acrylamide-co-ethylene dimethacrylate) monoliths. Biotechnol Bioeng 1999; 62: 30-5.

[24] Guerrouache M, Carbonnier B, Vidal-Madjar C, Millot M-C. In situ functionalization of $\mathrm{N}$-acryloxysuccinimide-based monolith for reversed-phase electrochromatography. J Chromatogr A 2007; 1149: 368-76.

[25] Guerrouache M, Millot M-C, Carbonnier B. Functionalization of Macroporous Organic Polymer Monolith Based on Succinimide Ester Reactivity for Chiral Capillary Chromatography: A Cyclodextrin Click Approach. Macromol Rapid Commun 2009; 30: 10913.

[26] Guerrouache M, Millot MC, Carbonnier B. Capillary columns for reversed-phase CEC prepared via surface functionalization of polymer monolith with aromatic selectors. J Sep Sci 2011; 34: 2271-8.

[27] Dao TTH, Guerrouache M, Carbonnier B. Thiol-yne Click Adamantane Monolithic Stationary Phase for Capillary Electrochromatography. Chin J Chem 2012; 30: 2281-4.

[28] Tijunelyte I, Babinot J, Guerrouache M, Valincius G, Carbonnier B. Hydrophilic monolith with ethylene glycol-based grafts prepared via surface confined thiol-ene click photoaddition. Polymer 2012; 53: 29-36.

[29] Kebe SI, Ben Boubaker M, Guerrouache M, Carbonnier B. Thiol-ene click chemistry for the design of diol porous monoliths with hydrophilic surface interaction ability: a capillary electrochromatography study. New J Chem 2016; 40: 6916-23.

[30] Mekhalif T, Kebe SI, Guerrouache M, Belattar N, Millot MC, Carbonnier B. Novel Monolithic Stationary Phase with Surface-Grafted Triphenyl Selector for Reversed-Phase Capillary Electrochromatography. Chromatographia 2016; 79: 1333-41.

[31] Poupart R, Le Droumaguet B, Guerrouache M, Carbonnier B. Copper nanoparticles supported on permeable monolith with carboxylic acid surface functionality: Stability and catalytic properties under reductive conditions. Mater Chem Phys 2015; 163: 446-52.

[32] Lav T-X, Carbonnier B, Guerrouache M, Grande D. Porous polystyrene-based monolithic materials templated by semi-interpenetrating polymer networks for capillary electrochromatography. Polymer 2010; 51: 5890-4.

[33] Lav T-X, Grande D, Gaillet C, Guerrouache M, Carbonnier B. Porous Poly(styrene-codivinylbenzene) Neutral Monolith: From Design and Characterization to Reversed-Phase Capillary Electrochromatography Applications. Macromol Chem Phys 2012; 213: 64-71.

[34] Zhang J, Wu L, Jing D, Ding J. A comparative study of porous scaffolds with cubic and spherical macropores. Polymer 2005; 46: 4979-85.

[35] Le Droumaguet B, Lacombe R, Ly H-B, Guerrouache M, Carbonnier B, Grande D. Engineering functional doubly porous PHEMA-based materials. Polymer 2014; 55: 373-9.

[36] Lin H-R, Kuo C-J, Yang CY, Shaw S-Y, Wu Y-J. Preparation of macroporous biodegradable PLGA scaffolds for cell attachment with the use of mixed salts as porogen additives. J Biomed Mater Res 2002; 63: 271-9. 
[37] Chow KS, Khor E. Novel Fabrication of Open-Pore Chitin Matrixes. Biomacromolecules 2000; 1: 61-7.

[38] LaNasa SM, Hoffecker IT, Bryant SJ. Presence of pores and hydrogel composition influence tensile properties of scaffolds fabricated from well-defined sphere templates. $\mathrm{J}$ Biomed Mater Res B 2011; 96B: 294-302.

[39] Apel P. Track etching technique in membrane technology. Radiat Meas 2001; 34: 55966.

[40] Matsen MW, Bates FS. Unifying Weak- and Strong-Segregation Block Copolymer Theories. Macromolecules 1996; 29: 1091-8.

[41] Bates FS, Fredrickson G. Block copolymers-designer soft materials. Physics Today 1999; 52: 32-8. Diblock Copolymers at Strong Segregation. Macromolecules 2006; 39: 2449-51.

[43] Lynd NA, Hillmyer MA. Influence of polydispersity on the self-assembly of diblock copolymers. Macromolecules 2005; 38: 8803-10.

[44] Lee JS, Hirao A, Nakahama S. Polymerization of monomers containing functional silyl groups. 5. Synthesis of new porous membranes with functional groups. Macromolecules 1988; 21: 274-6.

[45] Grande D, Le Droumaguet B. Design of functional nanoporous polymeric materials from sel-organized block copolymers. . In: Morton T, editor. Nanopores and nanoporous materials: Nova Science Publishers; 2016. p. 1-26.

[46] Gorzolnik B, Davidson P, Beurroies I, Denoyel R, Grande D. Novel Functional Mesoporous Materials Obtained from Nanostructured Diblock Copolymers. Macromol Symp 2010; 287: 127-34.

[47] Gorzolnik B, Penelle J, Grande D. Design of Mesoporous Materials with Controlled Porosity and Functionality from Nanostructured Diblock Copolymers. Polym Mater: Sci Eng 2007; 97: 223-4.

[48] Chuma A, Horn HW, Swope WC, Pratt RC, Zhang L, Lohmeijer BGG, et al. The Reaction Mechanism for the Organocatalytic Ring-Opening Polymerization of 1-Lactide Using a Guanidine-Based Catalyst: Hydrogen-Bonded or Covalently Bound? J Am Chem Soc 2008; 130: 6749-54.

[49] Cross ED, Allan LEN, Decken A, Shaver MP. Aluminum salen and salan complexes in the ring-opening polymerization of cyclic esters: Controlled immortal and copolymerization of rac- $\beta$-butyrolactone and rac-lactide. J Polym Sci, Part A: Polym Chem 2013; 51: 1137-46. [50] Zalusky AS, Olayo-Valles R, Taylor CJ, Hillmyer MA. Mesoporous Polystyrene Monoliths. J Am Chem Soc 2001; 123: 1519-20.

[51] Grande D, Penelle J, Davidson P, Beurroies I, Denoyel R. Functionalized ordered nanoporous polymeric materials: From the synthesis of diblock copolymers to their nanostructuration and their selective degradation. Microporous Mesoporous Mater 2011; 140: 34-9.

[52] Majdoub R, Antoun T, Droumaguet BL, Benzina M, Grande D. Original route to polylactide-polystyrene diblock copolymers containing a sulfonyl group at the junction between both blocks as precursors to functional nanoporous materials. React Funct Polym 2012; 72: 495-502.

[53] Sarkar A, Stefik M. Robust porous polymers enabled by a fast trifluoroacetic acid etch with improved selectivity for polylactide. Materials Chemistry Frontiers 2017; 1: 1526-33.

[54] Kuhn P, Antonietti M, Thomas A. Porous, Covalent Triazine-Based Frameworks Prepared by Ionothermal Synthesis. Angew Chem Int Ed 2008; 47: 3450-3. 
[55] Goldbach JT, Russell TP, Penelle J. Synthesis and Thin Film Characterization of Poly(styrene-block-methyl methacrylate) Containing an Anthracene Dimer Photocleavable Junction Point. Macromolecules 2002; 35: 4271-6.

[56] Yurt S, Anyanwu UK, Scheintaub JR, Coughlin EB, Venkataraman D. Scission of Diblock Copolymers into Their Constituent Blocks. Macromolecules 2006; 39: 1670-2.

[57] Zhang M, Yang L, Yurt S, Misner MJ, Chen JT, Coughlin EB, et al. Highly Ordered Nanoporous Thin Films from Cleavable Polystyrene-block-poly(ethylene oxide). Adv Mater 2007; 19: 1571-6. Its Self-Assembly into Nanoporous Thin Films. Macromolecules 2009; 42: 455-8.

[59] Schumers J-M, Gohy J-F, Fustin C-A. A versatile strategy for the synthesis of block copolymers bearing a photocleavable junction. Polym Chem 2010; 1: 161-3.

[60] Zhao H, Gu W, Sterner E, Russell TP, Coughlin EB, Theato P. Highly Ordered Nanoporous Thin Films from Photocleavable Block Copolymers. Macromolecules 2011; 44: 6433-40.

[61] Gamys CG, Schumers J-M, Vlad A, Fustin C-A, Gohy J-F. Amine-functionalized nanoporous thin films from a poly(ethylene oxide)-block-polystyrene diblock copolymer bearing a photocleavable o-nitrobenzyl carbamate junction. Soft Matter 2012; 8: 4486-93.

[62] Ouchi M, Konishi A, Takenaka M, Sawamoto M. Consecutive living polymerization from cationic to radical: a straightforward yet versatile methodology for the precision synthesis of "cleavable" block copolymers with a hemiacetal ester junction. Polym Chem 2012; 3: 2193-9.

[63] Poupart R, Benlahoues A, Le Droumaguet B, Grande D. Porous Gold NanoparticleDecorated Nanoreactors Prepared from Smartly Designed Functional Polystyrene-blockPoly(d,l-Lactide) Diblock Copolymers: Toward Efficient Systems for Catalytic Cascade Reaction Processes. ACS Appl Mater Interfaces 2017; 9: 31279-90.

[64] Satoh K, Poelma JE, Campos LM, Stahl B, Hawker CJ. A facile synthesis of clickable and acid-cleavable PEO for acid-degradable block copolymers. Polym Chem 2012; 3: 1890-8. [65] Goldbach JT, Lavery KA, Penelle J, Russell TP. Nano- to Macro-Sized Heterogeneities Using Cleavable Diblock Copolymers. Macromolecules 2004; 37: 9639-45.

[66] Le Droumaguet B, Poupart R, Grande D. "Clickable" thiol-functionalized nanoporous polymers: from their synthesis to further adsorption of gold nanoparticles and subsequent use as efficient catalytic supports. Polym Chem 2015; 6: 8105-11.

[67] Ryu J-H, Park S, Kim B, Klaikherd A, Russell TP, Thayumanavan S. Highly Ordered Gold Nanotubes Using Thiols at a Cleavable Block Copolymer Interface. J Am Chem Soc 2009; 131: 9870-1.

[68] Rao J, De S, Khan A. Synthesis and self-assembly of dynamic covalent block copolymers: towards a general route to pore-functionalized membranes. Chem Commun 2012; 48: 3427-9.

[69] Glassner M, Blinco JP, Barner-Kowollik C. Formation of nanoporous materials via mild retro-Diels-Alder chemistry. Polym Chem 2011; 2: 83-7.

[70] Fustin CA, Lohmeijer BGG, Duwez AS, Jonas AM, Schubert US, Gohy JF. Nanoporous Thin Films from Self-Assembled Metallo- Supramolecular Block Copolymers. Adv Mater 2005; 17: 1162-5.

[71] Mugemana C, Gohy J-F, Fustin C-A. Functionalized Nanoporous Thin Films from Metallo-Supramolecular Diblock Copolymers. Langmuir 2012; 28: 3018-23.

[72] Yu H, Stoffelbach F, Detrembleur C, Fustin C-A, Gohy J-F. Nanoporous thin films from ionically connected diblock copolymers. Eur Polym J 2012; 48: 940-4. 
[73] Montarnal D, Delbosc N, Chamignon C, Virolleaud M-A, Luo Y, Hawker CJ, et al. Highly Ordered Nanoporous Films from Supramolecular Diblock Copolymers with Hydrogen-Bonding Junctions. Angew Chem Int Ed 2015; 54: 11117-21.

[74] Zhao H, Gu W, Thielke MW, Sterner E, Tsai T, Russell TP, et al. Functionalized Nanoporous Thin Films and Fibers from Photocleavable Block Copolymers Featuring Activated Esters. Macromolecules 2013; 46: 5195-201.

[75] Dawson R, Cooper AI, Adams DJ. Nanoporous organic polymer networks. Prog Polym Sci 2012; 37: 530-63.

[76] McKeown NB, Budd PM. Polymers of intrinsic microporosity (PIMs): organic materials for membrane separations, heterogeneous catalysis and hydrogen storage. Chem Soc Rev 2006; 35: 675-83.

[77] Sakaushi K, Antonietti M. Carbon- and Nitrogen-Based Organic Frameworks. Acc Chem Res 2015; 48: 1591-600.

[78] Shen C, Yu H, Wang Z. Synthesis of 1,3,5,7-tetrakis(4-cyanatophenyl)adamantane and its microporous polycyanurate network for adsorption of organic vapors, hydrogen and carbon dioxide. Chem Commun 2014; 50: 11238-41.

[79] Zhang Y, Riduan SN, Ying JY. Microporous Polyisocyanurate and Its Application in Heterogeneous Catalysis. Chem Eur J 2009; 15: 1077-81. selective heterogeneous catalysis of the Knoevenagel reaction. Chem Commun 2016; 52: 7834-7.

[81] Carta M, Croad M, Bugler K, Msayib KJ, McKeown NB. Heterogeneous organocatalysts composed of microporous polymer networks assembled by Tröger's base formation. Polym Chem 2014; 5: 5262-6.

[82] Ben T, Ren H, Ma S, Cao D, Lan J, Jing X, et al. Targeted Synthesis of a Porous Aromatic Framework with High Stability and Exceptionally High Surface Area. Angew Chem Int Ed 2009; 48: 9457-60.

[83] Verde-Sesto E, Pintado-Sierra M, Corma A, Maya EM, de la Campa JG, Iglesias M, et al. First Pre-Functionalised Polymeric Aromatic Framework from Mononitrotetrakis(iodophenyl)methane and its Applications. Chem Eur J 2014; 20: 5111-20.

[84] Zeltinger J, Sherwood JK, Graham DA, Müeller R, Griffith LG. Effect of pore size and void fraction on cellular adhesion, proliferation, and matrix deposition. Tissue Eng 2001; 7: 557-72.

[85] Ruiz JAR, Marc-Tallon J, Pedros M, Dumon M. Two-step micro cellular foaming of amorphous polymers in supercritical CO2. J Supercrit Fluids 2011; 57: 87-94.

[86] Ly HB, Le Droumaguet B, Monchiet V, Grande D. Tailoring doubly porous poly(2hydroxyethyl methacrylate)-based materials via thermally induced phase separation. Polymer 2016; 86: 138-46.

[87] Huang Z-M, Zhang YZ, Kotaki M, Ramakrishna S. A review on polymer nanofibers by electrospinning and their applications in nanocomposites. Compos Sci Technol 2003; 63: 2223-53.

[88] Formhals A. Process and apparatus for preparing artificial threads. USA1934.

[89] Reneker DH, Chun I. Nanometre diameter fibres of polymer, produced by electrospinning. Nanotechnology 1996; 7: 216-23.

[90] Reneker DH, Yarin AL, Zussman E, Xu H. Electrospinning of Nanofibers from Polymer Solutions and Melts. In: Aref H, van der Giessen E, editors. Advances in Applied Mechanics: Elsevier; 2007. p. 43-346.

[91] Villarreal-Gómez LJ, Cornejo-Bravo JM, Vera-Graziano R, Grande D. Electrospinning as a powerful technique for biomedical applications: a critically selected survey. J Biomat Sci, Polym Ed 2016; 27: 157-76. 
[92] Bognitzki M, Czado W, Frese T, Schaper A, Hellwig M, Steinhart M, et al. Nanostructured Fibers via Electrospinning. Adv Mater 2001; 13: 70-2.

[93] Cameron NR, Sherrington DC. Non-aqueous high internal phase emulsions. Preparation and stability. J Chem Soc, Faraday Trans 1996; 92: 1543-7.

[94] Silverstein MS, Cameron NR. PolyHIPEs — Porous Polymers from High Internal Phase Emulsions. Encyclopedia of Polymer Science and Technology: John Wiley \& Sons, Inc.; 2002.

[95] Barby D, Haq Z. Low density porous cross-linked polymeric materials and their preparation. Google Patents; 1982.

[96] Krajnc P, Brown JF, Cameron NR. Monolithic Scavenger Resins by Amine Functionalizations of Poly(4-vinylbenzyl chloride-co-divinylbenzene) PolyHIPE Materials. Org Lett 2002; 4: 2497-500.

[97] Krajnc P, Štefanec D, Pulko I. Acrylic Acid "Reversed" PolyHIPEs. Macromol Rapid Commun 2005; 26: 1289-93.

[98] Kot E, Shirshova N, Bismarck A, Steinke JHG. Non-aqueous high internal phase emulsion templates for synthesis of macroporous polymers in situ filled with cyclic carbonate electrolytes. RSC Adv 2014; 4: 11512-9.

[99] R. Cameron N, C. Sherrington D. Preparation and glass transition temperatures of elastomeric PolyHIPE materials. J Mater Chem 1997; 7: 2209-12.

[100] Féral-Martin C, Birot M, Deleuze H, Desforges A, Backov R. Integrative chemistry toward the first spontaneous generation of gold nanoparticles within macrocellular polyHIPE supports (Au@polyHIPE) and their application to eosin reduction. React Funct Polym 2007; 67: 1072-82.

[101] Mehraban M, Zadhoush A, Abdolkarim Hosseini Ravandi S, Bagheri R, Heidarkhan Tehrani A. Preparation of porous nanofibers from electrospun polyacrylonitrile/calcium carbonate composite nanofibers using porogen leaching technique. J Appl Polym Sci 2013; 128: 926-33.

[102] Ly H-B, Le Droumaguet B, Monchiet V, Grande D. Designing and modeling doubly porous polymeric materials. Eur Phys J Spec Top 2015; 224: 1689-706.

[103] Ly HB, Le Droumaguet B, Monchiet V, Grande D. Facile fabrication of doubly porous polymeric materials with controlled nano- and macro-porosity. Polymer 2015; 78: 13-21.

[104] Ly HB, Halbardier L, Grande D. Biporous Crosslinked Polymers With Controlled Pore Size and Connectivity. Macromol Symp 2016; 365: 49-58.

[105] Ly HB, Poupart R, Halbardier L, Grande D. Functionalized Doubly Porous Networks: From Synthesis to Application in Heterogeneous Catalysis. Macromol Symp 2016; 365: 40-8. [106] Ly HB, Poupart R, Carbonnier B, Monchiet V, Le Droumaguet B, Grande D. Versatile functionalization platform of biporous poly(2-hydroxyethyl methacrylate)-based materials: Application in heterogeneous supported catalysis. React Funct Polym 2017; 121: 91-100. [107] Webb PA, Orr C. Analytical methods in fine particle technology: Micromeritics Instrument Corp; 1997.

[108] Washburn EW. Note on a Method of Determining the Distribution of Pore Sizes in a Porous Material. Proc Natl Acad Sci USA 1921; 7: 115-6.

[109] Moura MJ, Ferreira PJ, Figueiredo MM. Mercury intrusion porosimetry in pulp and paper technology. Powder Technol 2005; 160: 61-6. [110] Winslow DN. Advances in Experimental Techniques for Mercury Intrusion Porosimetry. In: Matijević E, Good RJ, editors. Surface and Colloid Science: Volume 13. Boston, MA: Springer US; 1984. p. 259-82.

[111] Rouquerol J, Avnir D, Fairbridge C, Everett D, Haynes J, Pernicone N, et al. Recommendations for the characterization of porous solids (Technical Report). Pure Appl Chem 1994; 66: 1739-58. 
[112] Feller C, Schouller E, Thomas F, Rouiller J, Herbillon AJ. N2-BET Specific Surface Areas of Some Low Activity Clay Soils and Their Relationships With Secondary Constituents and Organic Matter Contents. Soil Sci 1992; 153: 293-9.

[113] Kim KC, Yoon T-U, Bae Y-S. Applicability of using CO2 adsorption isotherms to determine BET surface areas of microporous materials. Microporous Mesoporous Mater 2016; 224: 294-301.

[114] Yanazawa H, Ohshika K, Matsuzawa T. Precision Evaluation in Kr Adsorption for Small BET Surface Area Measurements of Less Than $1 \mathrm{~m} 2$. Adsorption 2000; 6: 73-7.

[115] Brunauer S, Emmett PH, Teller E. Adsorption of Gases in Multimolecular Layers. J Am Chem Soc 1938; 60: 309-19.

[116] Barrett EP, Joyner LG, Halenda PP. The Determination of Pore Volume and Area Distributions in Porous Substances. I. Computations from Nitrogen Isotherms. J Am Chem Soc 1951; 73: 373-80.

[117] Iza M, Woerly S, Danumah C, Kaliaguine S, Bousmina M. Determination of pore size distribution for mesoporous materials and polymeric gels by means of DSC measurements: thermoporometry. Polymer 2000; 41: 5885-93.

[118] Brun M, Lallemand A, Quinson J-F, Eyraud C. A new method for the simultaneous determination of the size and shape of pores: the thermoporometry. Thermochim Acta 1977; 21: $59-88$.

[119] Jones BH, Lodge TP. Nanoporous Materials Derived from Polymeric Bicontinuous Microemulsions. Chem Mater 2010; 22: 1279-81.

[120] Wulff M. Pore size determination by thermoporometry using acetonitrile. Thermochim Acta 2004; 419: 291-4.

[121] Strange JH, Mitchell J, Webber JBW. Pore surface exploration by NMR. Magn Reson Imaging 2003; 21: 221-6.

[122] Dlapka M, Danninger H, Gierl C, Lindqvist B. Defining the pores in PM components. Metal Powder Report 2010; 65: 30-3.

[123] Vakifahmetoglu C, Colombo P. A Direct Method for the Fabrication of Macro-Porous SiOC Ceramics from Preceramic Polymers. Adv Eng Mater 2008; 10: 256-9.

[124] Moreno-Mañas M, Pleixats R. Formation of Carbon-Carbon Bonds under Catalysis by Transition-Metal Nanoparticles. Acc Chem Res 2003; 36: 638-43.

[125] Astruc D, Lu F, Aranzaes JR. Nanoparticles as Recyclable Catalysts: The Frontier between Homogeneous and Heterogeneous Catalysis. Angew Chem Int Ed 2005; 44: 785272.

[126] Takale BS, Bao M, Yamamoto Y. Gold nanoparticle (AuNPs) and gold nanopore (AuNPore) catalysts in organic synthesis. Org Biomol Chem 2014; 12: 2005-27.

[127] Daniel M-C, Astruc D. Gold Nanoparticles: Assembly, Supramolecular Chemistry, Quantum-Size-Related Properties, and Applications toward Biology, Catalysis, and Nanotechnology. Chem Rev 2004; 104: 293-346.

[128] Gawande MB, Goswami A, Felpin F-X, Asefa T, Huang X, Silva R, et al. Cu and CuBased Nanoparticles: Synthesis and Applications in Catalysis. Chem Rev 2016; 116: 3722811.

[129] Ranu BC, Dey R, Chatterjee T, Ahammed S. Copper Nanoparticle-Catalyzed Carbon $\square$ Carbon and Carbon $\square$ Heteroatom Bond Formation with a Greener Perspective. ChemSusChem 2012; 5: 22-44.

[130] Chen A, Holt-Hindle P. Platinum-Based Nanostructured Materials: Synthesis, Properties, and Applications. Chem Rev 2010; 110: 3767-804.

[131] Astruc D. Palladium Nanoparticles as Efficient Green Homogeneous and Heterogeneous Carbon-Carbon Coupling Precatalysts: A Unifying View. Inorg Chem 2007; 
[132] Munnik P, de Jongh PE, de Jong KP. Recent Developments in the Synthesis of Supported Catalysts. Chem Rev 2015; 115: 6687-718. Controlled Synthesis of Colloidal Silver Nanoparticles Based on Mechanistic Understanding. Chem Mater 2013; 25: 4679-89.

[134] Wuithschick M, Witte S, Kettemann F, Rademann K, Polte J. Illustrating the formation of metal nanoparticles with a growth concept based on colloidal stability. Phys Chem Chem Phys 2015; 17: 19895-900.

[135] Wuithschick M, Birnbaum A, Witte S, Sztucki M, Vainio U, Pinna N, et al. Turkevich in New Robes: Key Questions Answered for the Most Common Gold Nanoparticle Synthesis. ACS Nano 2015; 9: 7052-71.

[136] Kettemann F, Birnbaum A, Witte S, Wuithschick M, Pinna N, Kraehnert R, et al. Missing Piece of the Mechanism of the Turkevich Method: The Critical Role of Citrate Protonation. Chem Mater 2016; 28: 4072-81.

[137] Boutonnet M, Kizling J, Stenius P, Maire G. The preparation of monodisperse colloidal metal particles from microemulsions. Colloid Surface 1982; 5: 209-25.

[138] Shim I-W, Kim J-Y, Kim D-Y, Choi S. Preparation of Rh-containing polycarbonate films and the study of their chemical properties in the polymer. React Funct Polym 2000; 43: 71-8.

[139] Groppo E, Agostini G, Borfecchia E, Wei L, Giannici F, Portale G, et al. Formation and Growth of Pd Nanoparticles Inside a Highly Cross-Linked Polystyrene Support: Role of the Reducing Agent. J Phys Chem C 2014; 118: 8406-15.

[140] Chappa S, Bharath RS, Oommen C, Pandey AK. Dual-Functional Grafted Electrospun Polymer Microfiber Scaffold Hosted Palladium Nanoparticles for Catalyzing Redox Reactions. Macromol Chem Phys 2017; 218: 1600555.

[141] Poupart R, Nour El Houda D, Chellapermal D, Guerrouache M, Carbonnier B, Le Droumaguet B. Novel in-capillary polymeric monoliths arising from glycerol carbonate methacrylate for flow-through catalytic and chromatographic applications. RSC Adv 2016; 6: 13614-7.

[142] Xiao S, Xu W, Ma H, Fang X. Size-tunable Ag nanoparticles immobilized in electrospun nanofibers: synthesis, characterization, and application for catalytic reduction of 4-nitrophenol. RSC Adv 2012; 2: 319-27.

[143] Mora-Tamez L, Esquivel-Peña V, Ocampo AL, Rodríguez de San Miguel E, Grande D, de Gyves J. Simultaneous AuIII Extraction and In Situ Formation of Polymeric MembraneSupported $\mathrm{Au}$ Nanoparticles: A Sustainable Process with Application in Catalysis. ChemSusChem 2017; 10: 1482-93.

[144] Emin C, Remigy J-C, Lahitte J-F. Influence of UV grafting conditions and gel formation on the loading and stabilization of palladium nanoparticles in photografted polyethersulfone membrane for catalytic reactions. J Membr Sci 2014; 455: 55-63.

[145] Gu Y, Emin C, Remigy J-C, Favier I, Gómez M, Noble RD, et al. Hybrid Catalytic Membranes: Tunable and Versatile Materials for Fine Chemistry Applications. Mater TodayProc 2016; 3: 419-23.

[146] Liu Y, Guerrouache M, Kebe SI, Carbonnier B, Le Droumaguet B. Gold nanoparticlessupported histamine-grafted monolithic capillaries as efficient microreactors for flow-through reduction of nitro-containing compounds. J Mater Chem A 2017; 5: 11805-14.

[147] Khalil AM, Georgiadou V, Guerrouache M, Mahouche-Chergui S, Dendrinou-Samara C, Chehimi MM, et al. Gold-decorated polymeric monoliths: In-situ vs ex-situ immobilization strategies and flow through catalytic applications towards nitrophenols reduction. Polymer 2015; 77: 218-26. 
[148] Fang X, Ma H, Xiao S, Shen M, Guo R, Cao X, et al. Facile immobilization of gold nanoparticles into electrospun polyethyleneimine/polyvinyl alcohol nanofibers for catalytic applications. J Mater Chem 2011; 21: 4493-501.

[149] Nikbin N, Ladlow M, Ley SV. Continuous Flow Ligand-Free Heck Reactions Using Monolithic Pd [0] Nanoparticles. Org Process Res Dev 2007; 11: 458-62. Metathesis Polymerization Based Pore-Size-Selective Functionalization of Glycidyl Methacrylate Based Monolithic Media: Access to Size-Stable Nanoparticles for Ligand-Free Metal Catalysis. Chem Eur J 2010; 16: 4650-8.

[151] Budarin VL, Clark JH, Luque R, Macquarrie DJ, White RJ. Palladium nanoparticles on polysaccharide-derived mesoporous materials and their catalytic performance in $\mathrm{C}-\mathrm{C}$ coupling reactions. Green Chem 2008; 10: 382-7.

[152] Gu Y, Favier I, Pradel C, Gin DL, Lahitte J-F, Noble RD, et al. High catalytic efficiency of palladium nanoparticles immobilized in a polymer membrane containing poly(ionic liquid) in Suzuki-Miyaura cross-coupling reaction. J Membr Sci 2015; 492: 331-9. [153] Gu Y, Bacchin P, Lahitte J-F, Remigy J-C, Favier I, Gómez M, et al. Catalytic membrane reactor for Suzuki-Miyaura $\mathrm{C}-\mathrm{C}$ cross-coupling: Explanation for its high efficiency via modeling. AlChE J 2017; 63: 698-704.

[154] Zhang P, Weng Z, Guo J, Wang C. Solution-Dispersible, Colloidal, Conjugated Porous Polymer Networks with Entrapped Palladium Nanocrystals for Heterogeneous Catalysis of the Suzuki-Miyaura Coupling Reaction. Chem Mater 2011; 23: 5243-9.

[155] Du Z-L, Dang Q-Q, Zhang X-M. Heptazine-Based Porous Framework Supported Palladium Nanoparticles for Green Suzuki-Miyaura Reaction. Ind Eng Chem Res 2017; 56: 4275-80.

[156] Desforges A, Backov R, Deleuze H, Mondain-Monval O. Generation of Palladium Nanoparticles within Macrocellular Polymeric Supports: Application to Heterogeneous Catalysis of the Suzuki-Miyaura Coupling Reaction. Adv Funct Mater 2005; 15: 1689-95.

[157] Bandari R, Prager A, Höche T, Buchmeiser MR. Formation of Pd-Nanoparticles within the Pores of Ring Opening Metathesis Polymerization-Derived Polymeric Monoliths for Use in Organometallic Catalysis. ARKIVOC 2011.

[158] Bandari R, Buchmeiser MR. Polymeric monolith supported Pt-nanoparticles as ligandfree catalysts for olefin hydrosilylation under batch and continuous conditions. Catal Sci Technol 2012; 2: 220-6.

[159] Poupart R, Le Droumaguet B, Guerrouache M, Grande D, Carbonnier B. Gold nanoparticles immobilized on porous monoliths obtained from disulfide-based dimethacrylate: Application to supported catalysis. Polymer 2017; 126: 455-62.

[160] Floris P, Twamley B, Nesterenko PN, Paull B, Connolly D. Fabrication and characterisation of gold nano-particle modified polymer monoliths for flow-through catalytic reactions and their application in the reduction of hexacyanoferrate. Microchim Acta 2014; 181: 249-56.

[161] Taori VP, Bandari R, Buchmeiser MR. Selective Reduction of CO2 with Silanes over Platinum Nanoparticles Immobilised on a Polymeric Monolithic Support under Ambient Conditions. Chem Eur J 2014; 20: 3292-6.

[162] Desforges A, Deleuze H, Mondain-Monval O, Backov R. Palladium Nanoparticle Generation within Microcellular Polymeric Foam and Size Dependence under Synthetic Conditions. Ind Eng Chem Res 2005; 44: 8521-9.

[163] Gu YY, Remigy JC, Favier I, Gomez M, Noble RD, Lahitte JF. Membrane Reactor Based on Hybrid Nanomaterials for Process Intensification of Catalytic Hydrogenation Reaction: an Example of Reduction of the Environmental Footprint of Chemical Synthesis from a Batch to a Continuous Flow Chemistry Process. In: Chianese A, DiPalma L, Petrucci 
1 E, Stoller M, editors. International Conference on Nanotechnology Based Innovative 2 Applications for the Environment2016. p. 367-72.

3 [164] Huang Y, Ma H, Wang S, Shen M, Guo R, Cao X, et al. Efficient Catalytic Reduction 4 of Hexavalent Chromium Using Palladium Nanoparticle-Immobilized Electrospun Polymer 5 Nanofibers. ACS Appl Mater Interfaces 2012; 4: 3054-61.

6 [165] Cao Q, Xu Y, Liu F, Svec F, Fréchet JMJ. Polymer Monoliths with Exchangeable 7 Chemistries: Use of Gold Nanoparticles As Intermediate Ligands for Capillary Columns with 8 Varying Surface Functionalities. Anal Chem 2010; 82: 7416-21.

9 [166] Connolly D, Twamley B, Paull B. High-capacity gold nanoparticle functionalised 10 polymer monoliths. Chem Commun 2010; 46: 2109-11.

11 [167] Guerrouache M, Mahouche-Chergui S, Chehimi MM, Carbonnier B. Site-specific 12 immobilisation of gold nanoparticles on a porous monolith surface by using a thiol-yne click 13 photopatterning approach. Chem Commun 2012; 48: 7486-8.

14 [168] Merino E, Verde-Sesto E, Maya EM, Corma A, Iglesias M, Sánchez F. Mono15 functionalization of porous aromatic frameworks to use as compatible heterogeneous catalysts 16 in one-pot cascade reactions. Appl Catal, A 2014; 469: 206-12. [169] Xie Z, Wang C, deKrafft KE, Lin W. Highly Stable and Porous Cross-Linked Polymers for Efficient Photocatalysis. J Am Chem Soc 2011; 133: 2056-9. [170] Vankelecom IFJ. Polymeric Membranes in Catalytic Reactors. Chem Rev 2002; 102 : 3779-810.

21 [171] Cheng G, Hasell T, Trewin A, Adams DJ, Cooper AI. Soluble Conjugated Microporous 22 Polymers. Angew Chem Int Ed 2012; 51: 12727-31. [172] Cameron NR. High internal phase emulsion templating as a route to well-defined porous polymers. Polymer 2005; 46: 1439-49.

[173] Hainey P, Huxham IM, Rowatt B, Sherrington DC, Tetley L. Synthesis and ultrastructural studies of styrene-divinylbenzene Polyhipe polymers. Macromolecules 1991; 24: 117-21.

[174] Dzenis Y. Spinning Continuous Fibers for Nanotechnology. Science 2004; 304: 1917-9. [175] Mezhoud S, Paljevac M, Koler A, Le Droumaguet B, Grande D, Krajnc P. Novel 30 hypercrosslinking approach toward high surface area functional 2-hydroxyethyl methacrylate31 based polyHIPEs. React Funct Polym 2018; 132: 51-9. [176] Zeng J, Zhang Q, Chen J, Xia Y. A Comparison Study of the Catalytic Properties of Au-Based Nanocages, Nanoboxes, and Nanoparticles. Nano Lett 2010; 10: 30-5. 